\title{
1 Pseudomonas syringae enhances herbivory by suppressing the 2 reactive oxygen burst in Arabidopsis
}

4 Simon C. Groen ${ }^{a, b \neq}$, Parris T. Humphrey ${ }^{a}$, Daniela Chevasco ${ }^{b}$, Frederick M. Ausubel ${ }^{c, d}, N^{2}$ aomi E. Pierce ${ }^{b}$, 5 Noah K. Whiteman ${ }^{\mathrm{a}, \mathrm{b} \ddagger}$

$7 \quad{ }^{a}$ Department of Ecology and Evolutionary Biology, University of Arizona, Tucson, AZ 85721, United States

$8{ }^{b}$ Department of Organismic and Evolutionary Biology, Harvard University, Cambridge, MA 02138, United 9 States

10 'Department of Genetics, Harvard Medical School, Boston, MA 02115, United States

11 dDepartment of Molecular Biology, Massachusetts General Hospital, Boston, MA 02114, United States

$12{ }^{\ddagger}$ Corresponding authors: Department of Ecology and Evolutionary Biology, University of Arizona, Tucson, 13 Arizona 85721.

14 E-mail addresses: scgroen@email.arizona.edu, pth@email.arizona.edu, daniela578@gmail.com, 15 ausubel@molbio.mgh.harvard.edu,npierce@oeb.harvard.edu,whiteman@email.arizona.edu

16 Telephone number: +1 (520) 626-3950

\section{Abstract}

Plant-herbivore interactions have evolved in the presence of plant-colonizing microbes. These microbes can have important third-party effects on herbivore ecology, as exemplified by drosophilid flies that evolved from ancestors feeding on plant-associated microbes. Leaf-mining flies in the genus Scaptomyza, which is nested within the paraphyletic genus Drosophila, show strong associations with bacteria in the genus Pseudomonas, including Pseudomonas syringae. Adult females are capable of vectoring these bacteria between plants and larvae show a preference for feeding on $P$. syringaeinfected leaves. Here we show that Scaptomyza flava larvae can also vector $P$. syringae to and from feeding sites, and that they not only feed more, but also develop faster on plants previously infected with $P$. syringae. Our genetic and physiological data show that $P$. syringae enhances $S$. flava feeding on infected plants at least in part by suppressing anti-herbivore defenses mediated by reactive oxygen species.

\section{Keywords}

31 Arabidopsis thaliana; Drosophila melanogaster; Pseudomonas syringae; Scaptomyza; herbivore; plant 32 defense; reactive oxygen species 
Herbivory has arisen in only a third of living insect orders, but is associated with high rates of diversification when it evolves: nearly $25 \%$ of all named species on Earth are herbivorous insects (Farrell, 1998; Mitter et al., 1988). These radiations may be promoted by the dynamics of plant-herbivore interactions, involving the emergence of novel defensive chemicals in plants and counter-adaptations to these defensive compounds in herbivores (Ehrlich and Raven, 1964; Dobler et al., 2012). Although insect-targeting defensive chemicals are often lineage-specific, their induction is regulated in large part by a common defense response pathway mediated by the phytohormone jasmonic acid (JA, see Glossary in Table 1) (Wasternack and Hause, 2013). Anti-herbivore chemicals are often augmented by generalized plant defense mechanisms, including a protective cuticle, trichomes (Traw and Bergelson, 2003), and the production of reactive oxygen species (ROS) such as oxygen ions and peroxides in a ROS burst induced by herbivore feeding (Collins et al., 2010; Summers and Felton, 1998; Wu et al., 2013). Microbial pathogens and commensals of plants must also overcome these plant defenses (Cao et al., 2012; Melotto et al., 2006; Torres et al., 2006), and the induction and manipulation of the plant immune system by microbial colonizers may have facilitated the evolution of herbivory (McFall-Ngai et al., 2013; Thaler et al. 2012).

The full extent of the influence of microbes on the ecology and evolution of herbivory in insects (excluding vertically transmitted symbionts of hemipterans) is largely unknown (Hansen and Moran, 2014; McFall-Ngai et al., 2013). Bacterial associations are likely to be involved in enhancing herbivore nutrition, but microbes may also be involved in making plants more palatable through detoxification of defensive chemicals (Freeland and Janzen, 1974), or though suppression of their production. In case of the latter, at least two factors are proposed to shape the likelihood and route by which microbes influence herbivory: 1 ) whether resource acquisition by microbes requires living plant tissue (biotrophy) or the killing of plant tissue (necrotrophy), and 2) whether biotrophic microbes can successfully colonize the host plant (i.e., the microbes are compatible with the host) or not (i.e., the interaction is incompatible) (Lazebnik et al., 2014). Compatible biotrophic microbes tend to enhance feeding by chewing herbivores by suppressing the plant immune system with effectors or phytotoxins they deliver into plant cells (Cui et al., 2002; Groen et al., 2013; Lazebnik et al., 2014), whereas necrotrophic fungi and incompatible biotrophic microbes tend to reduce feeding (Cui et al., 2002; Lazebnik et al., 2014). In necrotrophic and incompatible biotrophic interactions, fungal phytotoxins or the recognition of effectors by the plant immune system trigger programmed cell death (PCD) in the plant, which is associated with a hypersensitive response (HR) and the release of ROS and plant defensive chemicals (Cui et al., 2002; Torres et al., 2006; Andersson et al., 2014). Such chemicals have broad-acting toxicity against microbes and animals in addition to their role as signaling molecules.

Herbivory has evolved several times independently in the family Drosophilidae from microbefeeding ancestors (Lapoint et al., 2013). Herbivorous species in the genus Scaptomyza, which is nested within the paraphyletic genus Drosophila, generally specialize on plants from the order Brassicales. They overcome the physical barrier of the leaf cuticle by laying eggs in leaf punctures, which adult females create using a dentate ovipositor (Whiteman et al., 2011). The females also feed on sap from these punctures, and this behavior may play a role in oviposition preference. After the eggs hatch, the larvae develop inside the leaves as leafminers, consuming the mesophyll tissue. To some extent adult females 
and larvae detoxify the lineage-specific defensive chemicals in the Brassicales, the glucosinolate-derived isothiocyanates (ITCs), using the mercapturic acid pathway (Gloss et al., 2014). One key enzyme in this pathway that has been characterized in Scaptomyza spp. is Glutathione S-transferase D1 (GstD1) (Gloss et al., 2014). Less is known about how Scaptomyza spp. larvae respond to the toxic effects of ROS, which can severely damage the peritrophic membrane that lines the midgut and protects insects from microbial attack (Mittapalli et al., 2007c; Summers and Felton, 1998). Evidence from D. melanogaster, the Hessian fly, and hemipteran and lepidopteran herbivores suggest that insect herbivores likely employ general xenobiotic metabolism pathways involving Glutathione $S$-transferases (including GstD1) to deactivate ROS species and downstream lipid peroxidation products (Landis et al., 2012; Lei and ZhuSalzman, 2015; Luan et al., 2013; Mittapalli et al., 2007a, b; Sawicki et al., 2003; Sykiotis and Bohmann, 2008).

The ancestors of the herbivorous drosophilids in the Scaptomyza lineage were microbe-feeders, and it is possible that the evolutionary transition to herbivory in this group was influenced in part by bacterial plant colonizers (O'Connor et al., 2014). Indeed, bacterial colonizers of Brassicales inhibit the formation of or detoxify ROS and ITCs, and have evolved several mechanisms to do this (Abramovitch et al., 2003; Fan et al., 2011; Gimenez-lbanez et al., 2009; Guo et al., 2012; Lewis et al., 2014; Tang et al., 1972; Xiang et al., 2008; Zhang et al., 2007).

A recent survey of Scaptomyza flava feeding on wild Barbarea vulgaris (Brassicaceae) in Flagstaff, Arizona, found that the fly's gut microbiota closely resemble the leaf microbiota of its host plants (O'Connor et al., 2014). This metamicrobiome is dominated by bacteria from the genus Pseudomonas, and encompasses the (hemi)biotrophic phytopathogen P. syringae. Although Scaptomyza and Pseudomonas spp. do not strictly depend on one another to colonize plants, some findings suggest that they can engage in a mutually beneficial relationship. P. syringae grows epiphytically and apoplastically, and colonizes the leaf after entering through the stomata, or wound sites, or through the vasculature after having colonized distal parts of the plant (Hirano and Upper, 2000; Misas-Villamil et al., 2011). Since both Scaptomyza spp. adult females and larvae create wound sites during feeding, insect feeding could promote the colonization of leaves by $P$. syringae. Indeed, adult female $S$. flava can act as vectors of $P$. syringae within and between plants (O'Connor et al., 2014). Additionally, adult S. flava females feed less and have a lower fecundity after treatment with antibiotics, suggesting that herbivory may be aided by the metabolic potential of gut-inhabiting microbes (O'Connor et al., 2014). These observations were paralleled by results from another field survey in herbivorous $S$. nigrita feeding on Cardamine cordifolia (Brassicaceae) (Humphrey et al., 2014). The leaf microbiota were similarly dominated by Pseudomonas spp., and larvae showed a preference for feeding on plants infected with $P$. syringae. Moreover, in nature, bacterial titers were consistently higher in leaves that had damage from leafmining S. nigrita.

Combined with our earlier laboratory studies, where we identified some of the mechanisms by which P. syringae can disrupt plant defense against insect herbivores (Cui et al., 2002, 2005; Groen et al., 2013), these observations pose the intriguing possibility that adult and larval Scaptomyza spp. may either directly inoculate their host plants with bacteria that facilitate feeding, or indirectly benefit from the defense-suppressive effects of prior Pseudomonas spp. infections. This pattern has been observed in other plant-herbivore interactions, in which herbivores benefit from the defense-suppressive effects of the microbes they transmit. These "suppressive" microbes comprise a wide range of obligate pathogens including viruses, phytoplasmas and bacteria (Body et al., 2013; Casteel et al., 2014; Kaiser et al., 2010; 
Kazan and Lyons, 2014; Li et al., 2014; Sugio et al., 2011; Ziebell et al., 2011). One well-studied example is the Colorado potato beetle, which inoculates its host plants with $P$. syringae and other bacteria that in turn suppress plant anti-herbivore defenses (Chung et al., 2013).

Table 1. Glossary

\begin{tabular}{|c|c|}
\hline \multicolumn{2}{|l|}{ Acronyms } \\
\hline COR & coronatine \\
\hline DAB & 3,3'-diaminobenzidine tetrahydrochloride \\
\hline ETI & effector-triggered immunity \\
\hline HR & hypersensitive response \\
\hline ITC & isothiocyanate \\
\hline JA & jasmonic acid \\
\hline JA-lle & jasmonic acid-isoleucine conjugate \\
\hline LAM & leaf area mined \\
\hline OPDA & 12-oxophytodienoic acid (JA precursor) \\
\hline PCD & programmed cell death \\
\hline PTI & pattern-triggered immunity \\
\hline ROS & reactive oxygen species \\
\hline SA & salicylic acid \\
\hline \multicolumn{2}{|l|}{ Arabidopsis thaliana } \\
\hline aos (or cyp74a/dde2) & mutant deficient in accumulation of JA and OPDA \\
\hline asFBP1.1 (or H4) & mutant with knocked-down expression of cell wall peroxidases \\
\hline coil-1 & mutant insensitive to JA-Ile and COR \\
\hline CYP81F2 & PTI marker gene typically associated with ROS and callose accumulation \\
\hline ein $2-1$ & mutant insensitive to ethylene \\
\hline myb51 & mutant deficient in accumulation of indole glucosinolates \\
\hline pad2-1 & mutant deficient in accumulation of glutathione \\
\hline pad4-1 & mutant deficient in accumulation of salicylic acid and ethylene \\
\hline pen4-1 (or pcs1/cad1) & mutant deficient in accumulation of phytochelatin \\
\hline pmr4-1 & mutant deficient in accumulation of callose \\
\hline rbohD & NADPH oxidase mutant \\
\hline rbohF & NADPH oxidase mutant \\
\hline $\operatorname{sid} 2-2$ & mutant deficient in accumulation of salicylic acid \\
\hline \multicolumn{2}{|l|}{ Pseudomonas syringae } \\
\hline Psm ES4326 cfa6 & mutant deficient in production of COR \\
\hline AvrPto, AvrPtoB, HopAl1 & P. syringae effectors suppressing accumulation of ROS and callose \\
\hline \multicolumn{2}{|l|}{ Scaptomyza flava } \\
\hline $\begin{array}{l}\text { Glutathione S-tranferase } \\
\text { D1 (GstD1) }\end{array}$ & xenobiotic metabolism gene important in detoxification \\
\hline Peritrophin A & integral to peritrophic membrane, physical antioxidant \\
\hline
\end{tabular}


How could $P$. syringae benefit insect herbivores? Several non-mutually exclusive mechanisms may be involved. Infections with many P. syringae strains, e.g. P. syringae pv. maculicola (Psm) ES4326, suppress JA-mediated insect defense signaling by activating plant immune signaling via salicylic acid (SA) (Chung et al., 2013; Groen et al., 2013; Wang et al., 2008). SA signaling generally has a suppressive effect on signaling by the major active JA molecule, the JA-isoleucine conjugate JA-lle, by a process of crosstalk known as SA/JA antagonism (Thaler et al., 2012). Consistent with SA/JA antagonism, oviposition and larval feeding by $S$. nigrita in the field increased on leaves pre-treated with SA, and decreased on leaves pre-treated with JA (Humphrey et al., 2014). Furthermore, larvae of S. flava show enhanced feeding and develop more quickly on mutants of the reference plant, Arabidopsis thaliana (Arabidopsis; Brassicaceae), that are deficient in JA signaling (Whiteman et al., 2011). This relatively simple narrative of SA/JA antagonism, is complicated however by the fact that although many strains of $P$. syringae activate SA-mediated defense responses, they also deploy a phytotoxin mimicking JA-lle, coronatine (COR). COR counters SA-mediated suppression of JA signaling leading to induced susceptibility to bacteria and a neutralization of the SA-mediated susceptibility to herbivores (Cui et al., 2005).

A second mechanism by which microbes could suppress host insect defenses that are specific to plants in the family Brassicaceae is the detoxification of ITCs formed in response to herbivory. ITCs can have strong negative effects on S. flava and other herbivores (Agrawal and Kurashige, 2003; Jander et al., 2001; Whiteman et al., 2011, 2012). ITCs also have anti-bacterial effects and several strains of $P$. syringae including Psm ES4326 employ SAX enzymes to detoxify those (Fan et al., 2011). Although SAXdependent detoxification of ITCs might benefit herbivores feeding on infected leaves, the SAX enzymes are not widely distributed among strains of $P$. syringae (Fan et al., 2011).

A third possible mechanism for microbe-mediated suppression of host defense is the detoxification of ROS or the inhibition of the ROS burst. P. syringae injects conserved effector proteins such as AvrPto, AvrPtoB and HopA1 into plant cells, which suppress the formation of ROS (Abramovitch et al., 2003; Baltrus et al., 2011; Gimenez-Ibanez et al., 2009; Xiang et al., 2008; Zhang et al., 2007), and produces catalases to detoxify them (Guo et al., 2012). ROS such as hydrogen peroxide directly damage both bacterial pathogens and insect herbivores (Cao et al., 2012; Liu et al., 2010; Mittapalli et al., 2007a; Summers and Felton, 1998). Furthermore, ROS act not only in cross-linking plant cell walls, which could toughen leaf tissue to herbivores, but also play a key role in orchestrating the overall plant immune response (Levine et al., 1994; Mhamdi et al., 2010; Torres et al., 2006; Wu et al., 2013). S. flava larvae and adult females also induce production of hydrogen peroxide during feeding (Whiteman et al., 2011). Suppression of the ROS burst by $P$. syringae might thus protect $S$. flava from oxidative damage and plant defensive mechanisms regulated by ROS, and thereby enhance feeding.

In the experiments described here, we focus on the potential role of the ROS burst in Arabidopsis $S$. flava - $P$. syringae interactions, and test the hypothesis that $P$. syringae associated with $S$. flava may make their shared host plant more palatable to the herbivore through suppressing the herbivoreinduced ROS burst. After establishing that larvae, like adult flies, can transmit $P$. syringae within and between leaves, we found that infection of Arabidopsis with $P$. syringae enhances S. flava feeding and development. By testing a set of candidate defense-related mutants in Arabidopsis, we discovered that S. flava feeding was increased on Arabidopsis mutants that were deficient in producing wild-type (WT) ROS responses. Levels of feeding on these mutants were similar to those on WT plants that had been infected with $P$. syringae. On the other hand, larval feeding was decreased on mutants with a lowered 
threshold to initiate (PCD). Cell death is an inevitable consequence when ROS levels reach a certain threshold and cause the release of additional ROS and ITCs (Andersson et al., 2014; Torres et al., 2006).

Congruent with a role for ROS in bacteria-induced susceptibility to herbivory, $P$. syringae suppressed the ROS burst generated in response to $S$. flava feeding, and $P$. syringae did not further promote larval feeding and development on intrinsically more palatable, engineered Arabidopsis plants, in which cell wall peroxidases are silenced and hydrogen peroxide production is disrupted. Furthermore, feeding by $S$. flava larvae on this ROS-deficient Arabidopsis line resulted in decreased expression of a xenobiotic detoxification gene in S. flava. Because pathogen- and herbivore-elicited ROS bursts form a widely conserved defense response among angiosperms (Torres et al., 2006), our findings are most likely relevant to other microbe-influenced interactions between plants and their attackers including insect herbivores and plant-parasitic nematodes (e.g. Luan et al., 2013; Vicente et al., 2013).

\section{Materials and methods}

\subsection{Biological material and growth conditions}

Plants: WT Arabidopsis accession Col-0 plants where grown as detailed in Whiteman et al. (2011). The loss-of-function Arabidopsis mutants aos (or cyp74a/dde2), ein2-1, pad2-1, pad4-1, pen4-1, pmr4-1, pad4-1 pmr4-1, rbohD, rbohF, and sid2-2 have been described and are in the Col-0 background (Alonso et al., 1999; Clay et al., 2009; Dewdney et al., 2000; Glazebrook and Ausubel, 1994; Glazebrook et al., 1996; Guzmán and Ecker, 1990; Howden and Cobbett, 1992; Jirage et al., 1999; Nishimura et al., 2003; Torres et al., 2002, 2005; Vatamaniuk et al., 1999; Vogel and Sommerville, 2000; Wildermuth et al., 2001; Zhou et al., 1998). The transgenic Arabidopsis reduction-of-function strain known as asFBP1.1 (or H4), in which expression of the cell wall-associated peroxidases $P R X 33, P R X 34$, and potentially other cell wall-associated peroxidases, is knocked down, has also been described and is in the Col-0 background (Bindschedler et al., 2006; Daudi et al., 2012; Mammarella et al., 2014). WT Barbarea vulgaris plants were grown in the same conditions as described for Arabidopsis from seeds that descended from plants that were field-collected in New Hampshire.

Insects: Information on the source population of Scaptomyza flava and fly rearing and experimental conditions can be found in Whiteman et al. (2011). For all experiments, with the exception of testing Arabidopsis mutants described in section 3.3, flies were reared on B. vulgaris. For these experiments, flies were reared on Arabidopsis.

Bacteria: We used a mutant of the laboratory strain P. syringae pv. maculicola (Psm) str. ES4326, which is closely related to $P$. syringae isolates associated with Scaptomyza spp. in the field (Humphrey et al., 2014). This mutant was the COR-deficient strain Psm ES4326 cfa6. We chose this COR-deficient mutant rather than the WT Psm ES4326 strain, because COR production is relatively rare among $P$. syringae isolates that colonize Brassicaceae plants (Baltrus et al., 2011; Hwang et al, 2005; Sarkar et al., 2006). The coronatine (COR)-deficient mutant Psm ES4326 cfa6 has been described by Cui and colleagues (2005). 
Psm ES4326 cfa6 bacteria were grown overnight in $2 \mathrm{~mL}$ liquid King's B supplemented with 50 $\mu \mathrm{g} \bullet \mathrm{ml}^{-1}$ kanamycin $(\mathrm{KB}+\mathrm{K} 50)$ at $28{ }^{\circ} \mathrm{C}$ in a shaking incubator $(225 \mathrm{rpm})$ for 18 hours prior to dilution and subsequent infection, as in Cui et al. (2005). The bacteria were then suspended in $10 \mathrm{mM} \mathrm{MgSO}_{4}+$ $0.01 \%$ Tween 20 at an optical density at $600 \mathrm{~nm}\left(\mathrm{OD}_{600}\right)$ of 0.2 . An $\mathrm{OD}_{600}$ of 0.2 corresponds to a density of c. $10^{6}$ colony-forming units $(\mathrm{cfu}) \cdot \mathrm{cm}^{-2}$ of leaf area (equivalent to an inoculum concentration of c. $10^{8}$ cfu• $\mathrm{ml}^{-1}$ ). A titer of $10^{6} \mathrm{cfu} \bullet \mathrm{cm}^{-2}$ of leaf area is regularly found for $P$. syringae in leaves damaged by Scaptomyza spp. larvae in the field (Humphrey et al., 2014), and this titer has previously been used in experiments in which a non-COR-producing $P$. syringae strain was inoculated epiphytically (see below) 215 (Melotto et al., 2006).

Leaves of four 10-week-old B. vulgaris plants ( $\mathrm{N}=2$ plants per treatment group) were either mocksuspension by gently painting the abaxial side of all the leaves in the $B$. vulgaris plants using sterile gloved fingers. We chose the abaxial side to mimic bacterial transmission by adult female flies as they mainly feed and oviposit on this side of the leaf (Whiteman et al., 2011).

Four days after inoculation, six two-day-old larvae per plant (total $\mathrm{N}=12$ per treatment group) were transferred from $B$. vulgaris nursing plants to the $B$. vulgaris source plants pre-inoculated with Psm ES4326 cfa6. Larvae were allowed to feed for two days on these infected source plants, after which three larvae per plant (total $\mathrm{N}=6$ per treatment group) were transferred again to non-inoculated $B$. vulgaris recipient plants to determine whether larvae can transfer Psm ES4326 cfa6 from infected to healthy plants. After feeding for four days in recipient plants, when the larvae pupated, a sample from each of the six recipient leaves was collected for dilution plating to quantify the abundance of Psm ES4326 cfa6 that had been transferred. For this and all subsequent assays, growth of Psm ES4326 cfa6 was assessed on $\mathrm{KB}+\mathrm{K} 50$ agar plates.

We enumerated bacterial growth within two of the 14 pre-inoculated source leaves at four days post inoculation just prior to the introduction of larvae from nursing plants (Figure 1D, Source plant prior to larval feeding). We also measured bacterial growth within eight of these 12 pre-inoculated source leaves two days after larvae had been introduced from nursing plants at six days post inoculation (Figure 1D, Source plant after larval feeding). Finally, we assessed bacterial growth within three of the six recipient leaves four days after larvae had been transferred from infected source plants (Figure 1D, Recipient plant after larval feeding). Bacterial growth was determined with dilution plating. We also included mock-treated leaves to control for cross-contamination.

In parallel, we collected larvae from the pre-infected source plants and transferred them directly onto $\mathrm{KB}+\mathrm{K} 50$ plates instead of transferring them into recipient plants. Two larvae per treatment group roamed freely on $\mathrm{KB}+\mathrm{K} 50$ plates for two days, after which plates were visually inspected for growth. The cuticles of two additional larvae per treatment group were washed with sterile $10 \mathrm{mM} \mathrm{MgSO}_{4}$ and then this wash was dilution-plated to see if bacteria were carried on the cuticle. Two final larvae per treatment group were surface-sterilized using $70 \% \mathrm{EtOH}$, and then also allowed to roam freely on $\mathrm{KB}+\mathrm{K} 50$ plates for two days. 
Larval feeding on WT and mutant Arabidopsis was measured using the leaf area-mined (LAM) assay as described in Whiteman et al. (2011) in which larvae were allowed to feed for four days after being transferred from nurse plants.

In a variant of this experiment, we measured larval feeding and development on WT and mutant Arabidopsis plants that were either pre-inoculated with Psm ES4326 cfa6 or mock-inoculated. Notably, bacterial infections and herbivory took place in the same leaves (co-infections). Prior to the start of an experiment, bacteria were prepared and inoculated as described in section 2.2 above. On the day of the inoculation of experimental plants, adult flies were allowed to mate and oviposit on non-inoculated WT Arabidopsis nurse plants for 24 hours. This time point was chosen to mimic the timing of events in nature, where adult females likely transmit $P$. syringae during feeding and oviposition on leaves that form the substrate for subsequent larval feeding (Humphrey et al., 2014; O'Connor et al., 2014). After four days, late first instar larvae were transferred to the experimental plants as described in Whiteman et al. (2011). Larval feeding was then measured after two days using the LAM assay.

After measuring LAM, larvae were allowed to complete their development in the experimental plants as described by Whiteman et al. (2011). Adult eclosion from pupae was assessed twenty days after the parental generation was allowed to oviposit on the nursing plants (Figure 2B), or was assessed every day until all pupae had eclosed (Figure 4B). A subset of leaves was harvested to verify Psm ES4326 cfa6 infection as described above.

\subsection{Detection of reactive oxygen species in Arabidopsis}

267

We measured the production of hydrogen peroxide in Arabidopsis after feeding by S. flava adult females. Experimental plants were either mock-inoculated or inoculated with Psm ES4326 cfa6 four days as described in section 2.2 prior to exposing them to adult S. flava. Adult S. flava were allowed to mate, feed and oviposit for 24 hours. Thereafter, three leaves per plant that received similar levels of damage and were matched developmentally ( $\mathrm{N}=3$ plants per treatment group) were harvested for analysis. In situ detection of hydrogen peroxide production in Arabidopsis leaves using 3,3'-diaminobenzidine tetrahydrochloride (DAB) was carried out following the methods described in Whiteman et al. (2011) and Daudi et al. (2012). We subsequently quantified the level of increase in DAB staining intensity around sites of feeding damage relative to the background levels of $D A B$ staining in undamaged surrounding tissue in the same leaves ( $N=9$ leaves per treatment sourced from 3 independently treated and processed plants) using ImageJ (Abràmoff et al., 2004). 
Expression of the xenobiotic metabolism genes Glutathione S-transferase D1 (GstD1) and Peritrophin A in S. flava larvae feeding on Arabidopsis WT and mutant plant lines was measured using real-time quantitative PCR (RT-qPCR). The materials, methods and primers used have been described in Whiteman et al. (2011). For each Arabidopsis line, RNA was isolated from whole bodies of 5-7 late second instar larvae feeding on these plant lines, which were divided over each of three biological replicates for each line. One exception was the asFBP1.1 line for which only two biological replicates of larvae feeding on this line were performed.

\subsection{Statistical analysis}

Statistical analysis was performed using R version 3.0.2 (R Core Development Team, 2012), and the R Commander package version 2.1-7 (Fox, 2005).

\section{Results}

3.1. Scaptomyza flava larvae can promote the spread and growth of Pseudomonas syringae within leaves

To determine whether $S$. flava larval movement facilitates the spread of $P$. syringae within leaves, we first characterized larval behavior. Although the larvae are less mobile than adult females, they still move frequently within leaves and occasionally between leaves of the same plant. S. flava larvae typically deposit their frass at the edges of the mines they create (Figures $1 \mathrm{~A} 1$ and $1 \mathrm{~A} 2$ ). Using the deposition of frass as evidence that an area was previously visited by larvae, we observed that larvae often leave the area of a mine where they have deposited frass for a few hours, but return later to resume feeding at these sites (Figure 1A3). This behavior is consistent with that described in the literature (Hendel, 1928; Hering, 1951a). We hypothesized that this larval movement behavior would promote the spread of $P$. syringae if it was already present inside the leaf, whether it had been deposited there by ovipositing and feeding adult females or through other mechanisms of colonization (Hirano and Upper, 2000; Humphrey et al., 2014; Morris et al., 2008; O'Connor et al., 2014).

To determine if larvae physically spread viable $P$. syringae, we released larvae that had been feeding on $B$. vulgaris leaves infected with $P$. syringae onto selective $\mathrm{KB}+\mathrm{K} 50$ plates. For these experiments and others described in this paper, we used a coronatine (COR) deficient, kanamycin resistant mutant of $P$. syringae pv. maculicola strain ES4326 (Psm ES4326 cfa6). We chose this strain because it closely 318 resembles $P$. syringae strains associated with S. flava in the wild (Humphrey et al., 2014) and because COR production is relatively rare among $P$. syringae isolates that colonize Brassicaceae plants (Baltrus et 
al., 2011; Hwang et al, 2005; Sarkar et al., 2006). Three days later, we observed that fluorescent Psm ES4326 cfa6 bacterial colonies developed wherever larvae traversed the agar surface (Figure 1B). We then investigated whether bacteria were transferred via the cuticle of the larvae (Hirano and Upper 2000). To do this, we rinsed larvae that had been feeding on Psm ES4326 cfa6-infected B. vulgaris leaves with sterile water and plated the washes. Three days after plating, colonies of Psm ES4326 cfa6 developed on plates that had been streaked with washes (Figure 1C), showing that larvae can mechanically spread bacteria. This experiment suggested that the larval behavior shown in Figure $1 \mathrm{~A}$ is conducive to the dissemination of bacterial colonizers within leaves through mechanical transfer via the cuticle.

We next performed a larval transfer experiment in which larvae that were feeding on $B$. vulgaris source leaves that had previously been inoculated epiphytically with Psm ES4326 cfa6 (Melotto et al. 2006) were transferred to non-inoculated recipient leaves of separate plants. Larvae successfully transmitted Psm ES4326 cfa6 in 3 out of 6 transfers. The transmissions of bacteria to recipient leaves show that in these cases Psm ES4326 cfa6 had entered the apoplastic space of the source leaves through the stomata as they could otherwise not have been picked up by larvae (Melotto et al., 2006). Moreover, when bacteria successfully established in the recipient leaves, they grew to titers that were the same or higher than those in the source leaves (Figure 1D). This is in line with results obtained in similar experiments involving three-way interactions between $P$. syringae, chewing herbivores and Brassicaceae host plants (Appel et al., 2014; Humphrey et al., 2014). Our results in the between-leaf transfer experiments further establish that larval foraging can promote the colonization of leaves by $P$. syringae.
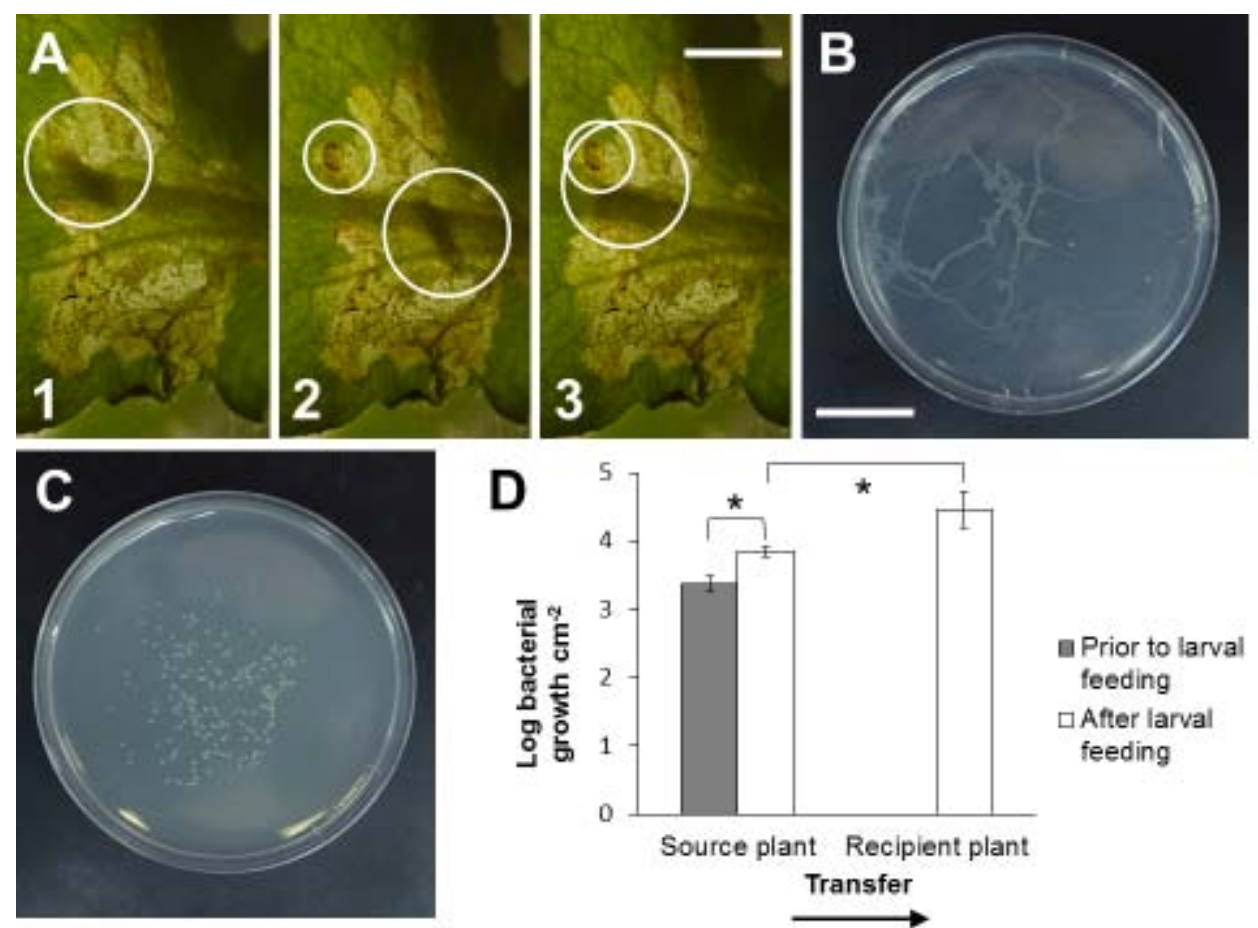
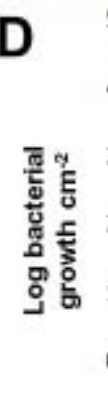

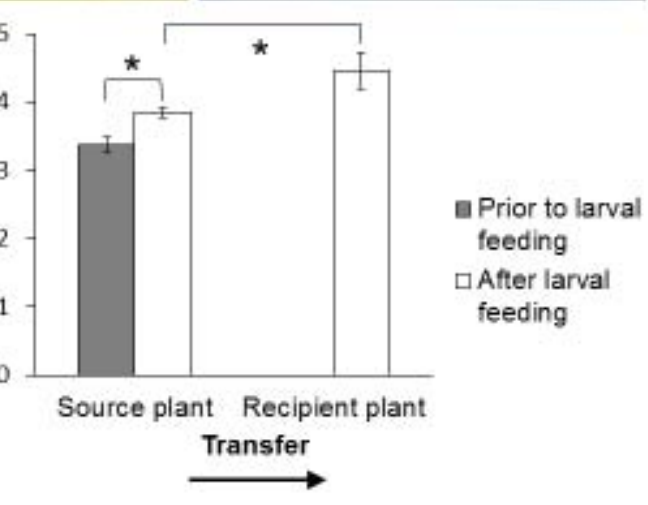

\section{2}


Fig. 1. Scaptomyza flava larvae can spread plant-colonizing bacteria within leaves. A) A S. flava larva deposits frass ([2] small white circle) upon leaving the feeding site in the $B$. vulgaris leaf ([1 and 2] large white circles). After having fed elsewhere in the leaf, the larva later returns to continue feeding at this site ([3] overlapping large and small white circles). B) S. flava larvae can spread plant-colonizing bacteria within leaves through the behavior described in (A). Bacteria attached to the larval cuticle can be deposited on other host plants, as shown here where a S. flava larva that fed on a leaf of a Psm ES4326 cfa6-infected B. vulgaris source plant was allowed to crawl on a selective King's B agar plate. C) Cuticle wash from a larva that had fed on a Psm ES4326 cfa6-infected leaf spread on a selective King's B agar plate. D) Mean accumulation of Psm ES4326 cfa6 after pre-inoculation of $B$. vulgaris source leaves prior to and after two days of larval feeding, and accumulation of Psm ES4326 cfa6 in recipient leaves on which larvae from infected source leaves were feeding. Error bars represent standard error of the mean. Asterisks indicate statistically significant differences in bacterial accumulation in pair-wise comparisons (two-tailed Student's $t$-test, $P<0.05$ ). Scale bars in (A) and (B) indicate $2 \mathrm{~cm}$; $(C)$ is depicted at the same scale as (B). Photo credit: Matthew Velazquez (A).

\subsection{Scaptomyza flava larvae perform better on leaves infected with Pseudomonas syringae}

We previously observed that Scaptomyza spp. can promote leaf colonization by $P$. syringae (Humphrey et al., 2014). This led us to test the hypothesis that inoculation of feeding sites with $P$. syringae might facilitate herbivory by S. flava. We addressed this by pre-inoculating leaves with Psm ES4326 cfa6, and assessing larval feeding and development.

Pre-inoculation of leaves with Psm ES4326 cfa6 led to enhanced feeding by S. flava larvae as determined by the leaf area-mined (LAM) assay (Figure 2A), which resulted in faster development into plants infected with a $P$. syringae isolate from the field (Humphrey et al., 2014). 

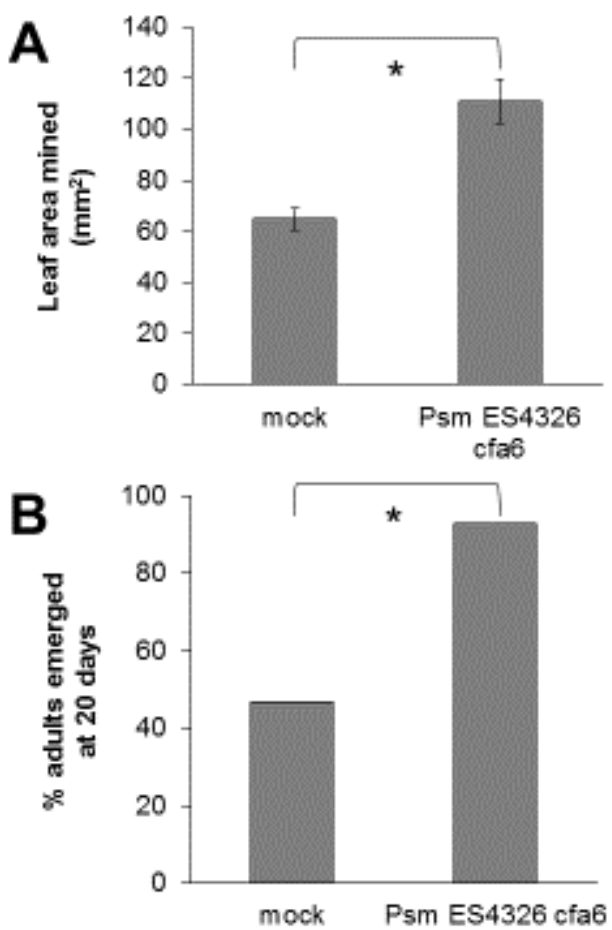

Fig. 2. Scaptomyza flava larvae consume more and develop faster in $P$. syringae-infected leaves. A) Mean leaf area mined (LAM) by S. flava larvae reared in wild-type (WT; Col-0) Arabidopsis leaves preinfected with Psm ES4326 cfa6 compared to LAM by larvae reared in mock-inoculated leaves. Larvae were transferred from WT nurse plants in the second instar into the experimental plants and allowed to feed for 48 hours. B) Percentage of S. flava pupae having eclosed as adults at 20 days after the day of oviposition in the nurse plants. Error bars represent standard error of the mean. Asterisks indicate a statistically significant difference (two-tailed Student's $t$-test, $P<0.05$ in (A); $\chi^{2}$ test, $P<0.05$ in (B)) between treatments ( $\mathrm{N}=15-20$ plants per treatment).

3.3. Scaptomyza flava second-and third-instar larval feeding rates correlate with plant capacity for ROS formation

Given that Psm ES4326 cfa6 infection enhanced feeding by S. flava, we tested a set of Arabidopsis mutants corresponding to candidate genes potentially involved in defense against $S$. flava larvae. We previously reported that larvae fed more on the JA signaling-deficient aos (or cyp74a/dde2) and coi1-1 mutants, and the glucosinolate-deficient myb51 mutant than on WT plants (Whiteman et al., 2011). This is consistent with findings that JA signaling- and glucosinolate-deficient mutants show enhanced susceptibility to a variety of chewing insect herbivores (Bodenhausen and Reymond, 2007; Gigolashvili et al., 2007; Groen et al., 2013; Müller et al., 2010).

We focused on testing mutants implicated in ROS-mediated immune responses. Our rationale for this was that ROS are generally produced upon the initiation of pattern-triggered immunity (PTI). This is the first layer of the plant immune system activated after recognition of conserved pathogen and/or 
insect elicitors such as chitin (Miya et al., 2007). ROS can have direct negative effects on insects and initiate downstream anti-herbivore defense responses that are regulated via JA, SA, ethylene and other hormones (Kim et al., 2014; Tsuda et al., 2009). The presence of crosstalk and feedback mechanisms within this regulatory network means that mutants with altered ROS production often have pleiotropic effects on JA signaling, regulation of PCD, and the production of defensive metabolites such as glucosinolates and callose.

The ein2-1, sid2-2 and pad4-1 mutants are affected in ROS production upon PTI initiation, but also show enhanced JA signaling due to a decrease in SA/JA antagonism (Cui et al., 2002; Groen et al., 2013; Kim et al., 2014; Mühlenbock et al., 2008; Tsuda et al., 2009; Wildermuth et al., 2001; Yi et al., 2014). It was therefore not unexpected that larvae consumed either equal amounts of or less leaf material on these mutants than on WT plants (Figure 3A). In contrast to the pad4-1 mutant, the callose-deficient mutant pmr4-1 has constitutively suppressed JA signaling due to high levels of SA (Nishimura et al., 2003), but a strongly enhanced capacity for producing ROS and for initiating PCD (Nishimura et al., 2003). In other words, the pmr4-1 and pad4-1 mutants have opposite phenotypes. The pmr4-1 mutant was not statistically different from WT plants with respect to levels of larval feeding (Figure 3B), consistent with the conclusion that enhanced susceptibility to feeding due to reduced JA signaling is balanced by enhanced resistance through a strongly increased capacity for ROS production, which has previously been observed for another mutant with similar characteristics, acd2 (Cui et al., 2002). A pad41 pmr4-1 double mutant exhibited enhanced larval feeding compared to the pad4-1 and pmr4-1 single mutants (Figure 3B), consistent with the hypothesis that, in the double mutant, the opposite effects of the mutant alleles on JA signaling, ROS formation, and PCD initiation negate one another (Nishimura et al., 2003).

The two main types of enzymes responsible for the ROS burst associated with defense-related responses are the NADPH oxidases $D$ and $F$ (RbohD and RbohF) (Torres et al., 2002, 2005), and cell wallassociated peroxidases including PRX33 and PRX34 (Bindschedler et al., 2006; Daudi et al. 2012; O'Brien et al., 2012b; Mammarella et al., 2014). The cell wall peroxidases form a major source of ROS during PTI (Daudi et al., 2012; O'Brien et al., 2012a, b), whereas the ROS produced by NADPH oxidases are involved in the suppression of HR-related PCD in addition to contributing to the ROS burst during both pattern(PTI) and effector-triggered immunity (ETI) (Daudi et al., 2012; O'Brien et al., 2012a, b; Torres et al., 2002, 2005). Interestingly, we found that $S$. flava larvae consumed c. $30 \%$ more leaf tissue on the cell wall peroxidase-deficient anti-sense transgenic line asFBP1.1 (Bindschedler et al., 2006; Daudi et al. 2012), which suggests that cell wall peroxidases are a major source of ROS during herbivore attack as they are during pathogen attack. Although the NADPH oxidases also produce ROS during herbivore and pathogen attack, and contribute to plant defense against aphids (Jaouannet et al., 2015; Miller et al., 2009; Torres et al., 2002, 2005), and caterpillars (Wu et al., 2013), S. flava larvae consumed equal amounts of leaf tissue on the rbohD and rbohF mutants vs. WT plants (Figure 3C). In these latter mutants, any reduction in ROS-mediated resistance to $S$. flava might be offset by the enhanced propensity for initiating PCD as is the case in the pmr4-1 mutant.

Another important prerequisite for ROS formation is the availability of glutathione (Dubreuil-Maurizi et al., 2011). Indeed, S. flava larvae consumed more leaf tissue in the glutathione-deficient mutant pad2-1 (Figure 3D), which produces lower levels of hydrogen peroxide after PTI initiation (DubreuilMaurizi et al., 2011; Parisy et al., 2007; Schlaeppi et al., 2008). Furthermore, larval feeding was diminished in the phytochelatin synthase-deficient pen4-1 mutant (Figure 3D). Phytochelatin-deficient 
mutants contain stabilized glutathione levels, and accumulate ROS and glucosinolates after PTI initiation (Clay et al., 2009; Dubreuil-Maurizi et al., 2011; Grill et al., 1989; Parisy et al., 2007). The JA produced after herbivore attack likely enhances glutathione production through induction of the expression of glutathione biosynthetic enzymes (Schlaeppi et al., 2008; Xiang and Oliver, 1998).

Despite the pleiotropic effects on JA signaling, regulation of PCD, and biosynthesis of callose and glucosinolates in some of the mutants analyzed here, when viewed together, these new data strongly 442 suggest a role for ROS, in particular hydrogen peroxide produced by cell wall-associated peroxidases, in 443 defense against $S$. flava.

444

445
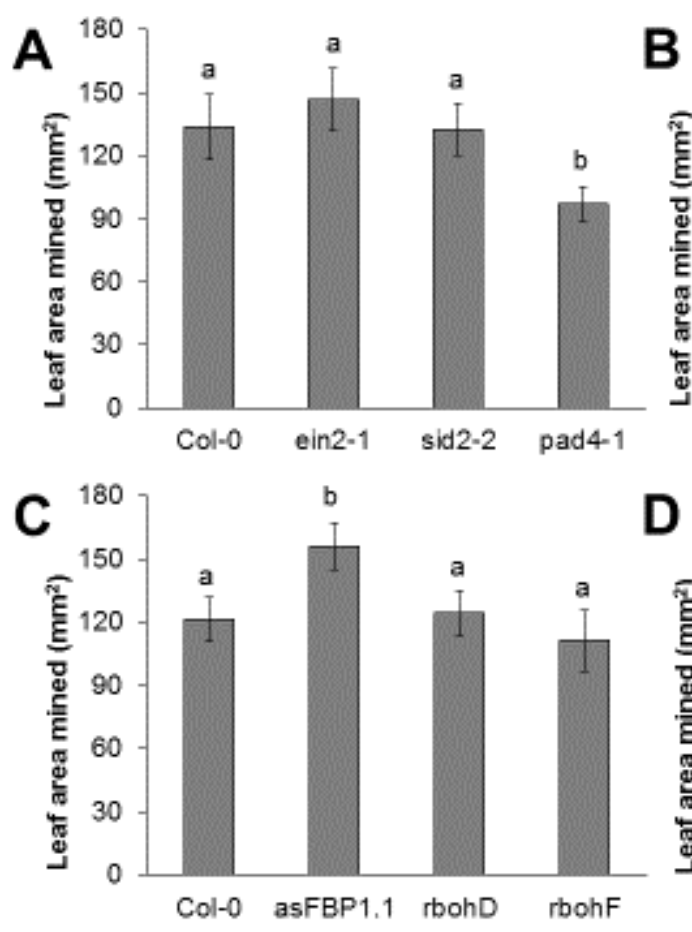
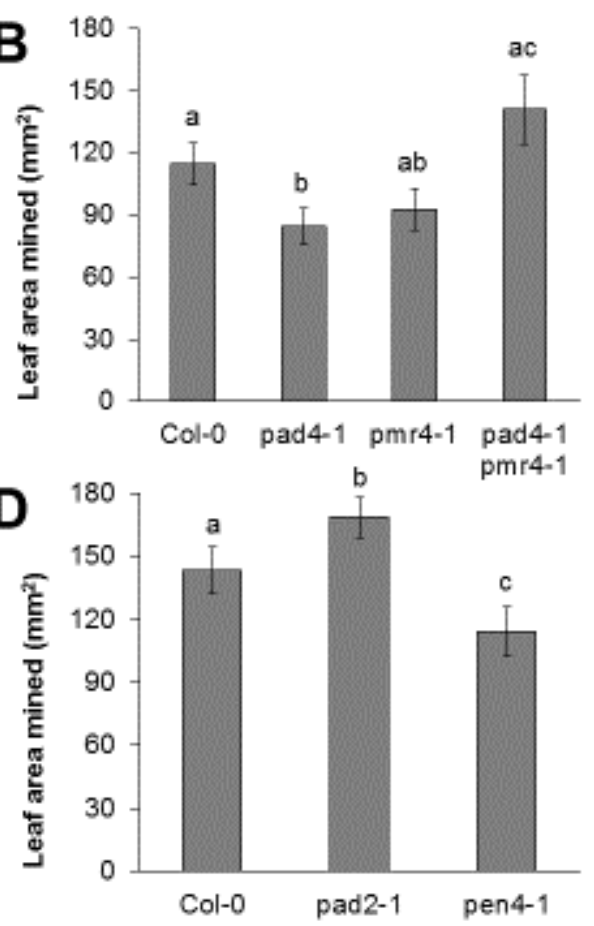

446

447 448

449

450

451

452

453

454

455

456

Fig. 3. Scaptomyza flava larval leaf consumption in Arabidopsis mutants varies with the plants' defensive potential. Mean leaf area mined (LAM) by S. flava larvae reared in Arabidopsis mutants relative to LAM by larvae reared in wild-type (WT; Col-0) plants. Larvae that had just reached the second instar were transferred from WT nurse plants to experimental and control plants and allowed to feed for 48 hours. Error bars represent standard error of the mean. Letters indicate a statistically significant difference (one-way ANOVA with post hoc Tukey's HSD tests; $\mathrm{P}<0.05)$ between treatments $(\mathrm{N}=15-20$ plants per treatment). 

production

461

462

463

464

465

466

467

468

469

470

471

472

473

474

475

476

477

478

479

480

481

482

483

484

485

486

487

488

489

490

Scaptomyza flava feeding activates the production of hydrogen peroxide (Whiteman et al. 2011), which plays important direct and indirect (regulatory) roles in anti-herbivore defense in Arabidopsis and other plant species (Collins et al., 2010; Summers and Felton, 1998; Wu et al., 2013). Several widely conserved $P$. syringae effectors prevent the formation of ROS by blocking upstream positive regulatory mechanisms (Abramovitch et al., 2003; Baltrus et al., 2011; Gimenez-Ibanez et al., 2009; Xiang et al., 2008; Zhang et al., 2007). In addition, P. syringae produces catalases that actively break down ROS (Guo et al., 2012). We therefore reasoned that the action of these bacterial enzymes and effectors might promote insect feeding by suppressing the accumulation of cell wall peroxidase-produced hydrogen peroxide or detoxifying it after herbivore attack.

We tested the hypothesis that $P$. syringae suppresses the generation or activity of ROS after herbivory by pre-inoculating WT and asFBP1.1 mutant plants with Psm ES4326 cfa6 or sterile $10 \mathrm{mM}$ $\mathrm{MgSO}_{4}$ as mock control and measuring LAM and development time. The asFBP1.1 mutant has no strong pleiotropic effects on JA signaling, callose deposition, or PCD initiation after infection with a diverse group of $P$. syringae isolates (Mammarella et al., 2014). In contrast to WT plants (see Fig. 2), if the primary reason that Psm ES4326 cfa6 causes enhanced feeding is because it suppresses ROS generation or activity, we predicted that Psm ES4326 cfa6 would not enhance the susceptibility of asFBP1.1 plants, which generate reduced amounts of ROS. To control for the possibility that the mock-inoculated asFBP1.1 would already be maximally susceptible to S. flava, we included mock- and Psm ES4326 cfa6inoculated aos mutant plants that are completely deficient in JA signaling. We previously found the aos mutant, which is deficient in the biosynthesis of JA, is highly susceptible to $S$. flava attack (Whiteman et al., 2011).

As hypothesized, pre-inoculation of Psm ES4326 cfa6 did not enhance $S$. flava feeding on the asFBP1.1 mutant (Figure 4A). Similarly, the rate of larval development was not significantly enhanced in the asFBP1.1 line following inoculation with Psm ES4326 cfa6 (Figure 4B). As expected, the aos mutant allowed even more feeding than the asFBP1.1 mutant (Figure $4 \mathrm{~A}$ ), allowing us to rule out the possibility that the asFBP1.1 line is maximally susceptible to $S$. flava, and therefore conclude that hydrogen peroxide plays a key role in Arabidopsis defense against S. flava. However, because Psm ES4326 cfa6 did not enhance susceptibility of the aos mutant either, it is also possible that $P$. syringae suppresses the JA signaling pathway by activating SA-mediated defense responses, i.e., by classic SA/JA antagonism. This is discussed in more detail below. 

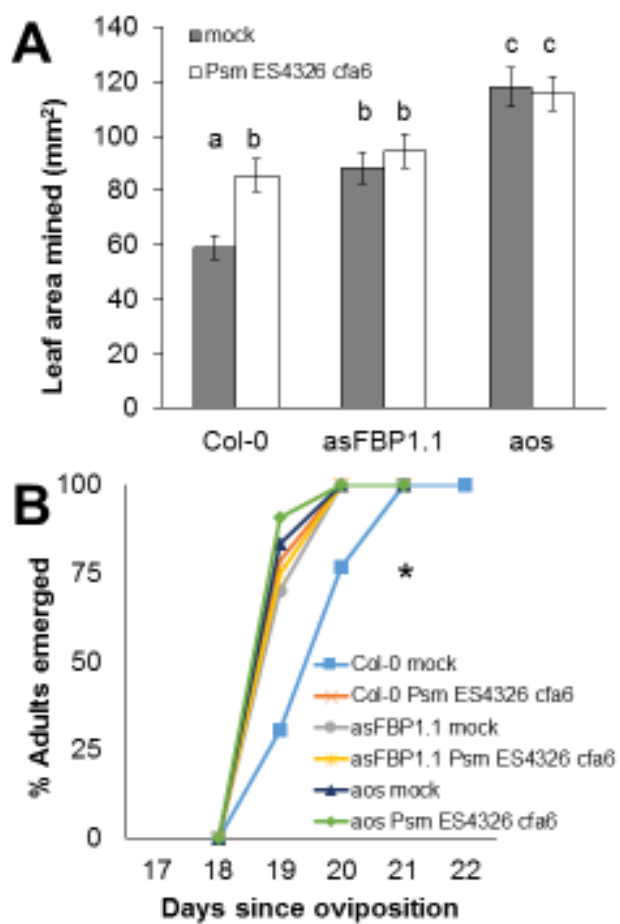

Fig. 4. Enhanced consumption of leaf material and accelerated development of $S$. flava larvae in $P$. syringae-infected leaves are not found in the asFBP1.1 and aos mutants of Arabidopsis infected with $P$. syringae. A) Mean leaf area mined (LAM) by $S$. flava larvae reared in wild-type (WT; Col-0) and mutant Arabidopsis leaves pre-infected with Psm ES4326 cfa6 compared to LAM by larvae reared in mockinoculated leaves. Larvae were transferred from WT nurse plants in the second instar into the experimental plants and allowed to feed for 48 hours. Error bars represent standard error of the mean. B) Percentage of $S$. flava pupae having eclosed as adults over time shown in days after the day of oviposition in the nurse plants. Letters in (A) indicate statistically significant differences (two-way ANOVA with post hoc Tukey's HSD tests, $\mathrm{P}<0.05)$. The asterisk in $(\mathrm{B})$ indicates a statistically significant difference between mock-inoculated Col-0 WT plants and the other treatment groups (two-way ANOVA with post hoc Tukey's HSD tests, $\mathrm{P}<0.05)$. $\mathrm{N}=15-20$ plants per treatment group.

To further determine whether bacterial suppression of herbivore-induced ROS accumulation underlies the beneficial effect of $P$. syringae on S. flava feeding, we tested whether Psm ES4326 cfa6 suppresses the ROS burst after herbivore damage. To do this, we visualized hydrogen peroxide production at S. flava feeding sites in plants that had either been pre-infected with Psm ES4326 cfa6 for four days as in the LAM and development time assays (Figures $4 \mathrm{~A}$ and $4 \mathrm{~B}$ ), or in plants that had been mock-inoculated. We focused on feeding damage caused by adult females, since these feeding sites are more amenable to quantifying ROS production using light microscopy and DAB staining than larval mines. Adult females create open wounds for feeding, whereas the larval mines are enclosed in the leaf 

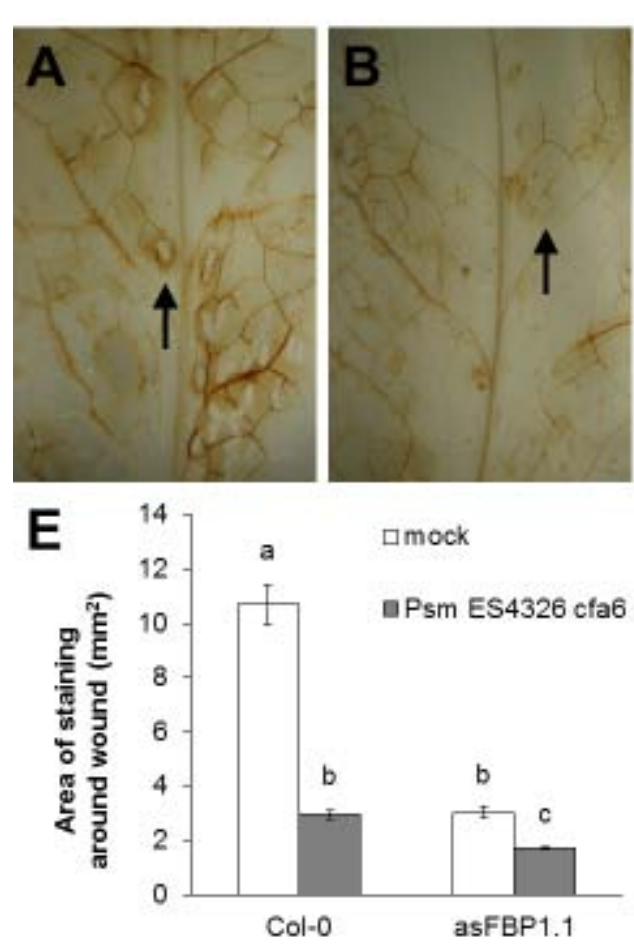
2011).

cuticle and various mesophyll cell layers. This means that it is difficult to accurately estimate hydrogen peroxide production in and around larval mines, because results can be confounded by the amount of tissue consumed by the larvae, which reduces the thickness of the leaf. This issue notwithstanding, adult females and larvae both induce the production of hydrogen peroxide upon feeding (Whiteman et al.,

Plants pre-infected with Psm ES4326 cfa6 produced significantly less hydrogen peroxide after subsequent feeding by S. flava than mock-inoculated plants (Figure 5A-B). This was quantified by measuring the area of positive DAB staining around sites of feeding damage (Figure 5E), and the DAB staining intensity around sites of feeding damage relative to the background levels of staining in undamaged surrounding tissue in the same leaves (Figure 5F). The same pattern was visible in the asFBP1.1 mutant (Figure 5C-F), albeit this mutant produces significantly less hydrogen peroxide than WT plants in response $S$. flava feeding without the presence of Psm ES4326 cfa6 (Figure 5E-F). The observation that prior infection with $P$. syringae also reduced the levels of DAB staining in the asFB1.1 line is consistent with previous reports showing that asFBP1.1 plants are not completely deficient in the production hydrogen peroxide (Bindschedler et al., 2006; Daudi et al., 2012; Mammarella et al., 2014). Although we did not sample enough eggs to quantify the effects of the presence of egg elicitors on ROS accumulation, the staining around sites of oviposition did not appear to differ visibly from staining around feeding sites without eggs (black arrows in Figure 5A-D). These results suggest that $P$. syringae promotes $S$. flava feeding by suppressing the ROS burst or by detoxification of ROS.
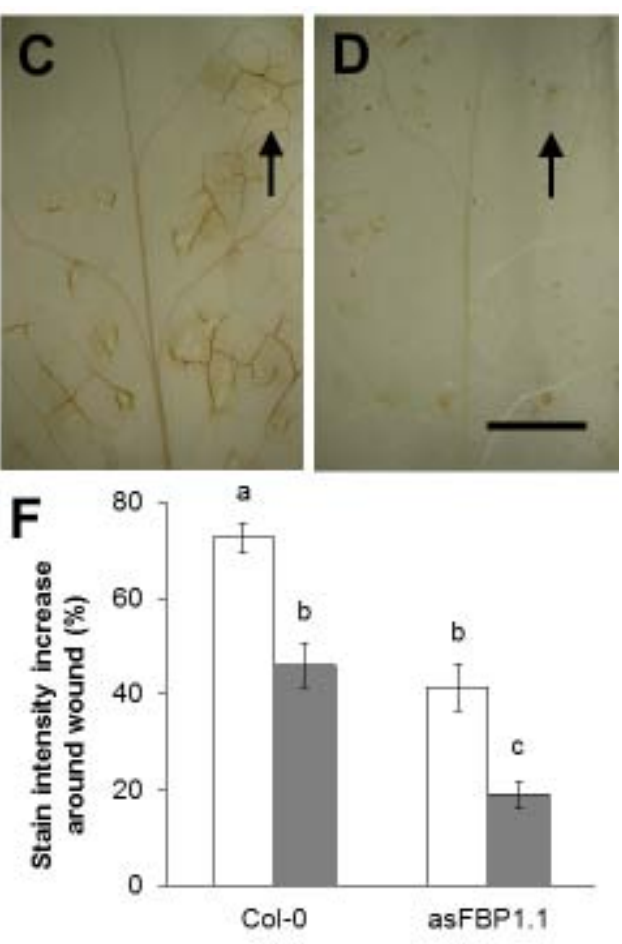

Fig. 5. Infection with $P$. syringae reduces plant hydrogen peroxide levels upon S. flava feeding. A-D) Staining of hydrogen peroxide production (brown coloration) using 3,3'-diaminobenzidine 
tetrahydrochloride (DAB) in leaves of wild-type (Col-0) (A-B) and asFBP1.1 mutant (C-D) Arabidopsis plants that were either pre-infected with Psm ES4326 cfa6 four days prior to insect feeding (B and D) or mock-inoculated ( $A$ and $C$ ), left with adult female $S$. flava flies for 24 hours. Note the difference in the relative contrast in staining around the feeding sites ("wounds") compared to the undamaged surrounding tissue between leaves pre-infected with Psm ES4326 cfa6 and mock-inoculated leaves, and the area of staining around individual feeding sites. Black arrows indicate sites of oviposition in which an egg was laid in the feeding site. E-F) Leaves representative for each treatment group, such as the leaves of which a close up is shown in (A-D), were selected for quantitative analysis. Letters in (E-F) indicate statistically significant differences (two-way ANOVA with post hoc Tukey's HSD tests, $P<0.05$ ). Error bars represent standard error of the mean. Scale bar in (D) for (A-D) indicates $5 \mathrm{~mm}$.

\subsection{Expression of Scaptomyza flava xenobiotic metabolism genes negatively correlates with levels of plant defense}

Finally, we tested whether the altered feeding of S. flava on Arabidopsis ROS mutants was reflected in the expression of xenobiotic metabolism genes in the larvae. We previously identified two candidate xenobiotic metabolism genes, Glutathione S-tranferase D1 (GstD1) and Peritrophin A. GstD1 is an important detoxification enzyme in Drosophila species, involved in xenobiotic and pesticide resistance, including resistance to ROS and downstream lipid peroxidation products (Landis et al., 2012; Mittapalli et al., 2007b; Sawicki et al., 2003), and to ITCs (Gloss et al., 2014). Peritrophin A is integral to the peritrophic membrane, which lines the midgut of most insects, and serves as a physical antioxidant in herbivorous insects protecting the epithelium from ROS (Summers, Felton, 1998). The expression of glutathione $S$-transferases and peritrophins changed in another herbivorous dipteran, the Hessian fly, in relation to levels of ROS produced by their wheat host plants (Mittapalli et al. 2007a, b, c). Furthermore, the expression of GstD1 and Peritrophin $A$ is upregulated in S. flava larvae in response to chitin pretreatment of Arabidopsis plants, which is known to lead to an ROS burst (Miya et al., 2007; Whiteman et al., 2011). The expression of these two xenobiotic metabolism genes is therefore consistent with the hypothesis that the insect midgut responds transcriptionally to differing levels of plant defensive chemicals such as ROS.

We found that expression of Peritrophin $A$ and GstD1 was downregulated in larvae reared on the cell wall-associated peroxidase-deficient line asFBP1.1 relative to those reared on the NADPH oxidase mutant rbohD (Figure 6). Conversely, expression of Peritrophin A was upregulated in larvae feeding on the NADPH oxidase mutants $r b o h D$ and $r b o h F$ compared to those consuming WT plant leaves (Figure 6). In all three mutants, the expression of GstD1 changed in the same direction as Peritrophin $A$, but the changes in GstD1 expression were not significant relative to larvae feeding on WT plants (Figure 6). 


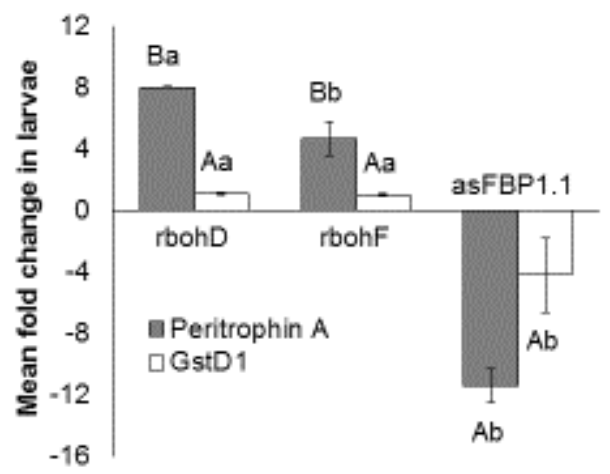

577 Fig. 6. Expression of two xenobiotic metabolism genes in S. flava negatively correlates with the 578 defensive potential of their host plants. The xenobiotic metabolism genes Peritrophin $A$ and Glutathione 579 S-transferase D1 (GstD1) are expressed at higher levels in S. flava larvae feeding on the rbohD and rbohF 580 Arabidopsis mutants and at lower levels in larvae feeding on the asFBP1.1 mutant. This correlates with the lower potential for reactive oxygen species (ROS) formation in asFBP1.1, and with the enhanced propensity for programmed cell death and concomitant release of ROS and other defensive chemicals in rbohD and rbohF. The figure shows the expression of Peritrophin A and GstD1 relative to the control housekeeping gene RpL32 in larvae reared on Arabidopsis mutants compared to wild-type (Col-0) plants. Error bars represent standard error of the mean. Capital letters indicate statistically significant differences in gene expression between larvae feeding on mutant plants compared to those feeding on WT plants; lowercase letters indicate statistically significant differences in gene expression between larvae feeding on the asFBP1.1 mutant and larvae feeding on the rbohD and $-F$ mutants (one-way ANOVA with post hoc Tukey's HSD tests; $P<0.05$ ).

\section{Discussion}

We found that $P$. syringae enhances Scaptomyza spp. herbivory by suppressing ROS-based plant defenses. However, the nature of the association between $P$. syringae and Scaptomyza spp. remains an open question: a key consideration is whether $P$. syringae can be vertically transmitted by Scaptomyza spp. Pseudomonas spp. are the dominant group of bacteria in the gut microbiota of S. flava. This is also the case in the Hessian fly (Bansal et al., 2011, 2014), an independently evolved dipteran herbivore. In the Hessian fly, vertical transmission of Pseudomonas spp. has been established (Bansal et al., 2011, 2014). Given that $P$. syringae has been found to die in the digestive tracts of Lepidoptera, and that icenucleating bacteria such as $P$. syringae might harm the insect in sub-zero temperatures (Mignon et al., 1998), it is unclear whether the association between Scaptomyza spp. and $P$. syringae could be maintained through vertical transmission. Nevertheless, Pseudomonas spp., including $P$. syringae isolates, form the dominant group of bacteria associated with Scaptomyza spp., and the leaves they 
Although in our larval performance assays we could only directly study the benefits of plant preinfection with $P$. syringae on the feeding and development of second and third instar S. flava larvae, $P$. syringae may also suppress anti-herbivore defenses during the egg and first instar stages. Eggs from Lepidoptera and Diptera (including Drosophila melanogaster) can activate PTI and induce ROS accumulation and callose deposition at the site of oviposition (Bruessow et al., 2010; Gouhier-Darimont et al., 2013; Little et al., 2007), leading to reduced larval performance (Geiselhardt et al., 2013). We have here and previously observed the accumulation of ROS at the sites of feeding and oviposition by adult female S. flava, and found that egg deposition activated expression of the PTI marker gene CYP81F2 (Whiteman et al., 2011), which is typically associated with ROS accumulation (Daudi et al., 2012). Since the process of oviposition increases the amount of ROS produced, this will likely make the ROS burstsuppressive effect of the bacteria on S. flava larval performance even more important.

The expression of CYP81F2 is also typically associated with callose deposition (Clay et al., 2009). We have incidentally observed desiccated first-instar larvae and eggs encased by callose in Barbarea vulgaris in nature (Groen and Whiteman, personal observation), and this has been reported in the literature as well (Hering, 1951b). In our larval performance assays we could not assess the potential suppression of callose deposition by $P$. syringae in response to $S$. flava eggs or first-instar larvae. However, ROS accumulation around adult female feeding sites, as well as around sites of egg deposition, was effectively suppressed by infection with Psm ES4326 cfa6 (Figure 5). Furthermore, a number of $P$. syringae effectors that suppress ROS accumulation, including AvrPto, AvrPtoB, and HopAl1, also suppress callose deposition (Gimenez-Ibanez et al., 2009; Xiang et al., 2008; Zhang et al., 2007). This suggests that $P$. syringae can suppress defenses induced by oviposition, and might thereby facilitate first instar as well as late instar larval feeding. Our data are in striking contrast to results obtained by studying three-way interactions between Arabidopsis, $P$. syringae pv. tomato DC3000, and the chewing lepidopteran herbivore Pieris brassicae, in which pre-infection with $P$. syringae induced resistance to herbivory (Hilfiker et al., 2014). It will be interesting to disentangle which mechanisms govern the variety of outcomes of three-way plant-microbe-herbivore interactions.

Given the lack of $P$. syringae-induced susceptibility to $S$. flava feeding in both the asFBP1.1 and the aos mutants, it is possible that $P$. syringae-induced susceptibility works at least in part through SA/JA antagonism. That is, infection by $P$. syringae elicits a strong SA-mediated defense response, which in turn antagonizes JA signaling, thereby phenocopying the aos mutant. According to this model, ROS and JA-mediated signaling function independently and additively to confer resistance to $S$. flava, and infection with $P$. syringae suppresses both ROS production and JA signaling. This seems unlikely, however, for the following reason: infection of asFBP1.1 knockdown plants with Psm ES4326 cfa6 does not lead to more $S$. flava feeding than the mock-infected asFBP1.1 controls. If Psm ES4326 cfa6 independently suppressed both hydrogen peroxide production and JA signaling, we would predict that the level of feeding on infected asFBP1.1 plants (and on infected WT plants) would have been similar to the higher levels observed on the aos mutant, but this was not the case (Fig. 4A).

Furthermore, the aos mutant is not only deficient in JA production, which at least partially accounts for the enhanced susceptibility to S. flava (Figure 4), but is also deficient in the biosynthesis of the JA precursor 12-oxophytodienoic acid (OPDA), which is an anti-herbivore defense compound and a regulator of anti-herbivore defense in its own right (Dabrowska et al., 2009; Park et al., 2013; Stintzi et al., 2001; Taki et al., 2005). OPDA signaling is necessary for glutathione homeostasis and, as in the case of the pad2-1 mutant, glutathione levels are diminished in the aos (or cyp74a/dde2-2) mutant, leading 
649

650

651

652

653

654

655

656

657

658

659

660

661

662

663

664

665

666

667

668

669

670

671

672

673

674

675

676

677

678

679

680

681

682

683

684

685

686

687

688

689

to reduced capacity for class III peroxidase expression (the class that includes cell wall peroxidases) and lower levels of ROS accumulation after attack (Dubreuil-Maurizi et al., 2011; Park et al., 2013; Taki et al., 2005). Thus, both the aos mutant and the asFBP1.1 knockdown line may be defective in ROS production, and the lack of $P$. syringae-induced susceptibility to $S$. flava in asFBP1.1 and aos plants may be a consequence of the diminished potential for ROS accumulation and defensive compounds that depend on ROS signaling for production. OPDA signaling was not the focus of the current study, but future work could elucidate its potential role in three-way plant-microbe-insect interactions.

In the case of the Arabidopsis NADPH oxidase mutants $r b o h D$ and $r b o h F$, enhanced expression of the Peritrophin A gene in S. flava larvae feeding on these mutants (Figure 6) contrasted with the data on larval leaf consumption on these mutants, which was unchanged (Figure $3 \mathrm{C}$ ), and suggests that activity of the NADPH oxidases do have an effect on S. flava physiology. The rbohD and rbohF mutants have less control over limiting the spread of PCD, which we have previously observed around S. flava feeding sites (Whiteman et al., 2011). The release of ROS and other defensive compounds, such as ITCs in the case of Arabidopsis (Andersson et al., 2014) from cells undergoing PCD around feeding sites could exert physiological costs on the herbivore (Agrawal and Kurashige, 2003; Summers and Felton, 1998; Whiteman et al., 2012). However, in this case these costs may fall within the limits of what the larvae can tolerate, so that larval feeding rates do not change. The two opposing roles of the NADPH oxidases in suppressing HR-related PCD and promoting PTI may explain the lack of a difference in the amount of leaf tissue consumed by $S$. flava larvae between the rboh mutants and WT plants. Overall, these data are consistent with previous reports showing that asFBP1.1 plants, but not rbohD and rbohF mutants, are significantly more susceptible to infection by a variety of bacterial and fungal pathogens (Bindschedler et al., 2006; Galletti et al., 2008; Pogany et al., 2009; Daudi et al., 2012; Mammarella et al., 2014).

\section{Conclusions}

We found that $S$. flava larvae can vector $P$. syringae within and between leaves, as was previously shown for adults (O'Connor et al., 2014), and that larval performance is enhanced when plants are infected with these bacteria. Enhanced larval feeding and more rapid larval development correlated with bacterial suppression of the plant ROS burst elicited by S. flava attack. A causal mechanism for this correlation was suggested by our finding that larval feeding was significantly enhanced in transgenic Arabidopsis asFBP1.1 plants engineered to produce low levels of hydrogen peroxide, but that preinfection with $P$. syringae did not increase larval feeding on asFBP1.1 plants. The increased larval feeding on asFBP1.1 was reflected in the decreased expression of a key gene involved in the insect's xenobiotic response. However, more work is needed to assess the relative importance of suppression of the ROS burst by $P$. syringae in facilitating herbivory compared to other possible mechanisms for the bacterial suppression of anti-herbivore defenses such as the suppression of JA signaling, callose deposition, and the detoxification of ITCS.

Given the apparently close association of $P$. syringae and $S$. flava on their shared host plants and their potentially mutually beneficial relationship, there is a clear potential for either partner to use the other to manipulate and colonize new host plants, as has been described for numerous viral and bacterial plant pathogens and their insect vectors (Casteel et al., 2014; Chung et al., 2013; Kazan and 
Lyons, 2014; Mauck et al., 2012; Palukaitis et al., 2013; Sugio et al., 2011; Ziebell et al., 2011). In this way, Scaptomyza spp. might complement their own offensive mechanisms (e.g. proteinaceous effectors, phytohormones or phytohormone analogs secreted with the saliva) with those offered by microbes, as has been observed in other plant-herbivore and plant-plant parasitic nematode interactions (e.g. Favery et al., this issue; Guiguet et al., this issue; Harris et al., 2015; Kazan and Lyons, 2014; Zhang et al., this issue; Zhao et al., this issue). Future field-based experiments such as those described by Humphrey et al. (2014) and O'Connor et al. (2014) will allow us to gauge the extent and relevance of these associations.

\section{Acknowledgements}

We thank Jennifer Bush and Andrew Gloss for providing Arabidopsis and B. vulgaris plants and adult S. flava, Hoon Pyon for assistance with experiments, and Paul Nabity for advice on conducting DAB staining. We are grateful to Andrew Gloss, Tim O'Connor, Philippe Reymond and Sophie Zaaijer for valuable feedback on manuscript drafts and members of the Whiteman, Ausubel and Pierce laboratories for enlightening discussions. We acknowledge Matthew Velazquez for allowing the use of still images from his documentary about the Whiteman laboratory. NKW was supported by a Kirschstein National Research Service Award (NRSA) from the National Institutes of Health (F32Al069732 to NKW), the National Geographic Society (Grant 9097-12 to NKW), and the University of Arizona (Faculty Seed Grant, Center for Insect Science Seed Grant, and laboratory set-up grant to NKW). FMA and NKW were supported by grants from the National Science Foundation (grants MCB-0519898 and IOS 0929226 to FMA, and grant DEB-1256758 to NKW), and FMA was supported by an R37 grant from the National Institutes of Health (grant GM48707 to FMA). PTH and NKW were supported by the NSF (grant DEB1309493 to PTH and NKW). NKW, SCG, FMA and NEP were supported by a grant from the Harvard University's Provost Fund for Interfaculty Collaboration, and a grant from the Harvard University Science and Engineering Committee Seed Fund for Interdisciplinary Science. NKW and SCG were supported by the John Templeton Foundation (Grant ID \#41855 to NKW). The funding sources had no involvement in the study design; the collection, analysis and interpretation of data; the writing of the report; or in the decision to submit the article for publication. Data accessibility: all raw data will be deposited in the Dryad data repository (doi \# pending).

\section{References}

Abràmoff, M.D., Magalhães, P.J., Ram, S.J., 2004. Image processing with ImageJ. Biophotonics International, 11(7), 36-43.

Abramovitch, R.B., Kim, Y.J., Chen, S., Dickman, M.B., Martin, G.B., 2003. Pseudomonas type III effector AvrPtoB induces plant disease susceptibility by inhibition of host programmed cell death. EMBO Journal, 22(1), 60-69. 
Agrawal, A.A., Kurashige, N.S., 2003. A role for isothiocyanates in plant resistance against the specialist herbivore Pieris rapae. Journal of Chemical Ecology 29(6), 1403-1415. of ethylene and stress responses in Arabidopsis. Science, 284(5423):2148-2152.

Andersson, M.X., Nilsson, A.K., Johansson, O.N., Bozta, G., Adolfsson, L.E., Pinosa, F., Garcia Petit, C., Aronsson, H., Mackey, D., Tör, M., Hamberg, M., Ellerström, M., 2014. Involvement of the electrophilic isothiocyanate sulforaphane in Arabidopsis local defense responses. Plant Physiology, pp.114.251892.

Appel, H.M., Maqbool, S.B., Raina, S., Jagadeeswaran, G., Acharya, B.R., Hanley, J.C. Jr, Miller, K.P., Hearnes, L., Jones, A.D., Raina, R., Schultz, J.C., 2014. Transcriptional and metabolic signatures of Arabidopsis responses to chewing damage by an insect herbivore and bacterial infection and the consequences of their interaction. Frontiers in Plant Science, 5, 441.

Baltrus, D.A., Nishimura, M.T., Romanchuk, A., Chang, J.H., Mukhtar, M.S., Cherkis, K., Roach, J., Grant, S.R., Jones, C.D., Dangl, J.L., 2011. Dynamic evolution of pathogenicity revealed by sequencing and comparative genomics of 19 Pseudomonas syringae isolates. PLoS Pathogens, 7(7), e1002132. reveals the predominance of Pseudomonadaceae in gut microbiome of a gall midge. Pathogens, 3(2), 459-472.

Bansal R., Hulbert, S., Schemerhorn, B., Reese, J.C., Whitworth, R.J., Stuart, J.J., Chen, M.S., 2011. Hessian fly-associated bacteria: transmission, essentiality, and composition. PLoS ONE, 6(8), e23170.

Bindschedler, L.V., Dewdney, J., Blee, K.A., Stone, J.M., Asai, T., Plotnikov, J., Denoux, C., Hayes, T., Gerrish, C., Davies, D.R., Ausubel, F.M., Bolwell, G.P., 2006. Peroxidase-dependent apoplastic oxidative burst in Arabidopsis required for pathogen resistance. Plant Journal, 47(6), 851-863. herbivores in Arabidopsis. Molecular Plant Microbe Interactions, 20(11), 1406-1420.

Body, M., Kaiser, W., Dubreuil, G., Casas, J., Giron, D., 2013. Leaf-miners co-opt microorganisms to enhance their nutritional environment. Journal of Chemical Ecology, 39(7), 969-977.

Bruessow, F., Gouhier-Darimont, C., Buchala, A., Metraux, J.P., Reymond, P., 2010. Insect eggs suppress plant defence against chewing herbivores. Plant Journal, 62(5), 876-885.

Cao, B., Liu, J., Qin, G., Tian, S., 2012. Oxidative stress acts on special membrane proteins to reduce the viability of Pseudomonas syringae pv tomato. Journal of Proteome Research, 11(10), 4927-4938. of Turnip mosaic virus improves growth and reproduction of the aphid vector, Myzus persicae (green peach aphid). Plant Journal, 77(4), 653-663.

760 Chung, S.H., Rosa, C., Scully, E.D., Peiffer, M., Tooker, J.F., Hoover, K., Luthe, D.S., Felton, G.W., 2013. 761 Herbivore exploits orally secreted bacteria to suppress plant defenses. Proceedings of the National 762 Academy of Sciences, 110, 15728-15733. 
Clay, N.K., Adio, A.M., Denoux, C., Jander, G., Ausubel, F.M., 2009. Glucosinolate metabolites required for an Arabidopsis innate immune response. Science, 323(5910), 95-101.

Collins, R.M., Afzal, M., Ward, D.A., Prescott, M.C., Sait, S.M., Rees, H.H., Tomsett, A.B., 2010. Differential proteomic analysis of Arabidopsis thaliana genotypes exhibiting resistance or susceptibility to the insect herbivore, Plutella xylostella. PLoS ONE, 5(4), e10103.

Cui, J., Bahrami, A.K., Pringle, E.G., Hernandez-Guzman, G., Bender, C.L., Pierce, N.E., Ausubel, F.M., 2005. Pseudomonas syringae manipulates systemic plant defenses against pathogens and herbivores. Proceedings of the National Academy of Science of the USA, 102(5), 1791-1796.

Cui, J., Jander, G., Racki, L.R., Kim, P.D., Pierce, N.E., Ausubel, F.M., 2002. Signals involved in Arabidopsis resistance to Trichoplusia ni caterpillars induced by virulent and avirulent strains of the phytopathogen Pseudomonas syringae. Plant Physiology, 129(2), 551-564.

Dabrowska, P., Freitak, D., Vogel, H., Heckel, D.G., Boland, W., 2009. The phytohormone precursor OPDA is isomerized in the insect gut by a single, specific glutathione transferase. Proceedings of the National Academy of Sciences of the USA, 106(38), 16304-16309.

Daudi, A., Cheng, Z., O'Brien, J.A., Mammarella, N.D., Khan, S., Ausubel, F.M., Bolwell, G.P., 2012. The apoplastic oxidative burst peroxidase in Arabidopsis is a major component of pattern-triggered immunity. Plant Cell, 24(1), 275-287.

Dewdney, J., Reuber, T.L., Wildermuth, M.C., Devoto, A., Cui, J., Stutius, L.M., Drummond, E.P., Ausubel, F.M., 2000. Three unique mutants of Arabidopsis identify eds loci required for limiting growth of a biotrophic fungal pathogen. Plant Journal, 24(2), 205-218.

Dobler, S., Dalla, S., Wagschal, V., Agrawal, A.A., 2012. Community-wide convergent evolution in insect adaptation to toxic cardenolides by substitutions in the Na,K-ATPase. Proceedings of the National Academy of Science of the USA, 109(32), 13040-13045.

Dubreuil-Maurizi, C., Vitecek, J., Marty, L., Branciard, L., Frettinger, P., Wendehenne, D., Meyer, A.J., Mauch, F., Poinssot, B., 2011. Glutathione deficiency of the Arabidopsis mutant pad2-1 affects oxidative stress-related events, defense gene expression, and the hypersensitive response. Plant Physiology, 157(4), 2000-2012.

Ehrlich, P.R., Raven, P.H., 1964. Butterflies and plants: a study in coevolution. Evolution, 18(4), 586-608.

Fan, J., Crooks, C., Creissen, G., Hill, L., Fairhurst, S., Doerner, P., Lamb, C., 2011. Pseudomonas sax genes overcome aliphatic isothiocyanate-mediated non-host resistance in Arabidopsis. Science, 331(6021), $1185-1188$.

Farrell, B.D., 1998. "Inordinate fondness" explained: Why are there so many beetles? Science, 281(5376), 555-559.

Favery, B., Quentin, M., Jaubert-Possamai, S., Abad, P., this issue. Gall-forming root-knot nematodes effectors hijack key plant cellular functions to induce multinucleate and hypertrophied feeding cells. Journal of Insect Physiology. 
Fox, J., 2005. The R Commander: a basic-statistics graphical user interface to R. Journal of Statistical Software, 14(9), 1-42.

Freeland, W.J., Janzen, D.H., 1974. Strategies in herbivory by mammals: the role of plant secondary compounds. American Naturalist, 108(961), 269-289.

Galletti, R., Denoux, C., Gambetta, S., Dewdney, J., Ausubel, F.M., De Lorenzo, G., Ferrari, S., 2008. The AtrbohD-mediated oxidative burst elicited by oligogalacturonides in Arabidopsis is dispensable for the activation of defense responses effective against Botrytis cinerea. Plant Physiology, 148(3), 1695-1706.

Geiselhardt, S., Yoneya, K., Blenn, B., Drechsler, N., Gershenzon, J., Kunze, R., Hilker, M., 2013. Egg laying of cabbage white butterfly (Pieris brassicae) on Arabidopsis thaliana affects subsequent performance of the larvae. PLoS ONE, 8(3), e59661.

Gigolashvili, T., Berger, B., Mock, H.P., Müller, C., Weisshaar, B., Flügge, U.I., 2007. The transcription factor HIG1/MYB51 regulates indolic glucosinolate biosynthesis in Arabidopsis thaliana. Plant Journal 50(5), 886-901.

Gimenez-Ibanez, S., Hann, D.R., Ntoukakis, V., Petutschnig, E., Lipka, V., Rathjen, J.P., 2009. AvrPtoB targets the LysM receptor kinase CERK1 to promote bacterial virulence on plants. Current Biology, 19(5), 423-429.

Glazebrook, J., Ausubel, F.M., 1994. Isolation of phytoalexin-deficient mutants of Arabidopsis thaliana and characterization of their interactions with bacterial pathogens. Proceedings of the National Academy of Science of the USA, 91(19), 8955-8959.

Glazebrook, J., Rogers, E.E., Ausubel, F.M., 1996. Isolation of Arabidopsis mutants with enhanced disease susceptibility by direct screening. Genetics, 143(2), 973-982.

Gloss, A.D., Vassao, D.G., Hailey, A.L., Nelson Dittrich, A.C., Schramm, K., Reichelt, M., Rast, T.J., Weichsel, A., Cravens, M.G., Gershenzhon, J., Monfort, W.R., Whiteman N.K., 2014. Evolution in an ancient detoxification pathway is coupled with a transition to herbivory in the Drosophilidae. Molecular Biology and Evolution, 31, 2441-2456.

Gouhier-Darimont, C., Schmiesing, A., Bonnet, C., Lassueur, S., Reymond, P., 2013. Signalling of Arabidopsis thaliana response to Pieris brassicae eggs shares similarities with PAMP-triggered immunity. Journal of Experimental Botany, 64(2), 665-674.

Grill, E., Löffler, S., Winnacker, E.L., Zenk, M.H., 1989. Phytochelatins, the heavy-metal-binding peptides of plants, are synthesized from glutathione by a specific gamma-glutamylcysteine dipeptidyl transpeptidase (phytochelatin synthase). Proceedings of the National Academy of Science of the USA, 86(18), 6838-6842.

Groen, S.C., Whiteman, N.K., Bahrami, A.K., Wilczek, A.M., Cui, J., Russell, J.A., Cibrian-Jaramillo, A., Butler, I.A., Rana, J.D., Huang, G.H., Bush, J., Ausubel, F.M., Pierce, N.E., 2013. Pathogen-triggered ethylene signaling mediates systemic-induced susceptibility to herbivory in Arabidopsis. Plant Cell, 25(11), 4755-4766. 
Guiguet, A., Dubreuil, G., Harris, M.O., Appel, H.M., Schultz, J.C., Pereira, M.H., Giron, D., this issue. Shared weapons of blood- and plant-feeding insects: surprising commonalities for manipulating hosts. Journal of Insect Physiology

Guo, M., Block, A., Bryan, C.D., Becker, D.F., Alfano, J.R., 2012. Pseudomonas syringae catalases are collectively required for plant pathogenesis. Journal of Bacteriology, 194(18), 5054-5064.

Guzmán, P., Ecker, J.R., 1990. Exploiting the triple response of Arabidopsis to identify ethylene-related mutants. Plant Cell, 2(6), 513-523.

Hansen, A.K., Moran, N.A., 2014. The impact of microbial symbionts on host plant utilization by herbivorous insects. Molecular Ecology, 23(6), 1473-1496.

He, Y., Chung, E.H., Hubert, D.A., Tornero, P., Dangl, J.L., 2012. Specific missense alleles of the Arabidopsis jasmonic acid co-receptor COI1 regulate innate immune receptor accumulation and function. PLoS Genetics, 8(10), e1003018.

Hendel, F., 1928. Über die minierenden europäischen Scaptomyza - Arten und ihre Biologie (Diptera). Zoologischer Anzeiger, 76, 289-302.

Hering, E.M., 1951a. Biology of leaf miners. Junk-Gravenhage; Berlin.

Hering, E.M., 1951b. Veränderungen in pflanzlichen Geweben unter dem Einfluss minierender InsektenLarven. Svensk botanisk Tidskrift, 45, 42-73.

Hilfiker, O., Groux, R., Bruessow, F., Kiefer, K., Zeier, J., Reymond, P., 2014. Insect eggs induce a systemic acquired resistance in Arabidopsis. Plant Journal, 80(6), 1085-1094.

Hirano, S.S., Upper, C.D., 2000. Bacteria in the leaf ecosystem with emphasis on Pseudomonas syringae a pathogen, ice nucleus, and epiphyte. Microbiology and Molecular Biology Reviews, 64(3), 624-653.

Howden, R., Cobbett, C.S., 1992. Cadmium-sensitive mutants of Arabidopsis thaliana. Plant Physiology, 100(1), 100-107.

Humphrey, P.T., Nguyen, T.T., Villalobos, M.M., Whiteman, N.K., 2014. Diversity and abundance of phyllosphere bacteria are linked to insect herbivory. Molecular Ecology, 23, 1497-1515.

Hwang, M.S., Morgan, R.L., Sarkar, S.F., Wang, P.W., Guttman, D.S., 2005. Phylogenetic characterization of virulence and resistance phenotypes of Pseudomonas syringae. Applied and Environmental Microbiology, 71(9), 5182-5191.

Jander, G., Cui, J., Nhan, B., Pierce, N.E., Ausubel, F.M., 2001. The TASTY locus on chromosome 1 of Arabidopsis affects feeding of the insect herbivore Trichoplusia ni. Plant Physiology, 126(2), 890-898.

Jaouannet, M., Morris, J.A., Hedley, P.E., Bos, J.I., 2015. Characterization of Arabidopsis transcriptional responses to different aphid species reveals genes that contribute to host susceptibility and non-host resistance. PLoS Pathogens, 11(5), e1004918.

Jirage, D., Tootle, T.L., Reuber, T.L., Frost, L.N., Feys, B.J., Parker, J.E., Ausubel, F.M., Glazebrook, J., 1999. Arabidopsis thaliana PAD4 encodes a lipase-like gene that is important for salicylic acid signaling. Proceedings of the National Academy of Science of the USA, 96(23), 13583-13588. 
871 Kaiser, W., Huguet, E., Casas, J., Commin, C., Giron, D., 2010. Plant green-island phenotype induced by 872 leaf-miners is mediated by bacterial symbionts. Proceedings of the Royal Society B: Biological Sciences, 873 277(1692), 2311-2319.

874 Kazan, K., Lyons, R., 2014. Intervention of phytohormone pathways by pathogen effectors. Plant Cell, 875 26(6), 2285-2309.

876 Kim, Y., Tsuda, K., Igarashi, D., Hillmer, R.A., Sakakibara, H., Myers, C.L., Katagiri, F., 2014. Mechanisms 877 underlying robustness and tunability in a plant immune signaling network. Cell Host \& Microbe, 15(1), 878 84-94.

879 Landis, G., Shen, J., Tower, J., 2012. Gene expression changes in response to aging compared to heat 880 stress, oxidative stress and ionizing radiation in Drosophila melanogaster. Aging, 4(11), 768-789.

881 Lapoint, R.T., O'Grady, P.M., Whiteman, N.K., 2013. Diversification and dispersal of the Hawaiian 882 Drosophilidae: evolution of Scaptomyza. Molecular Phylogenetics and Evolution, 69, 95-108.

883 Lazebnik, J., Frago, E., Dicke, M., van Loon, J.J., 2014. Phytohormone mediation of interactions between 884 herbivores and plant pathogens. Journal of Chemical Ecology, 40(7), 730-741.

885 Lei, J., Zhu-Salzman, K., 2015. Enhanced aphid detoxification when confronted by a host with elevated 886 ROS production. Plant Signaling \& Behavior, 10(4), e1010936.

887 Levine, A., Tenhaken, R., Dixon, R., Lamb, C., 1994. $\mathrm{H}_{2} \mathrm{O}_{2}$ from the oxidative burst orchestrates the plant 888 hypersensitive disease resistance response. Cell, 79(4), 583-593.

889 Lewis, J.D., Wilton, M., Mott, G.A., Lu, W., Hassan, J.A., Guttman, D.S., Desveaux, D., 2014. 890 Immunomodulation by the Pseudomonas syringae HopZ type III effector family in Arabidopsis. PLoS 891 ONE, 9(12), e116152.

892 Li, R., Weldegergis, B.T., Li, J., Jung, C., Qu, J., Sun, Y., Qian, H., Tee, C., van Loon, J.J., Dicke, M., Chua, 893 N.H., Liu, S.S., Ye, J., 2014. Virulence factors of geminivirus interact with MYC2 to subvert plant 894 resistance and promote vector performance. Plant Cell, 26(12), 4991-5008.

895 Little, D., Gouhier-Darimont, C., Bruessow, F., Reymond, P., 2007. Oviposition by pierid butterflies 896 triggers defense responses in Arabidopsis. Plant Physiology, 143(2), 784-800.

897 Liu, X., Williams, C.E., Nemacheck, J.A., Wang, H., Subramanyam, S., Zheng, C., Chen, M.S., 2010. 898 Reactive oxygen species are involved in plant defense against a gall midge. Plant Physiology, 152(2), 985899999.

900 Luan, J.B., Wang, Y.L.,Wang ,J., Wang, X.W., Liu, S.S., 2013. Detoxification activity and energy cost is 901 attenuated in whiteflies feeding on tomato yellow leaf curl China virus-infected tobacco plants. Insect 902 Molecular Biology, 22(5), 597-607.

903 Mammarella, N.D., Cheng, Z., Fu, Z.Q., Daudi, A., Bolwell, G.P., Dong, X., Ausubel, F.M., 2014. Apoplastic 904 peroxidases are required for salicylic acid-mediated defense against Pseudomonas syringae. 905 Phytochemistry, pii, S0031-9422(14)00280-5. 
Maruta, T., Inoue, T., Tamoi, M., Yabuta, Y., Yoshimura, K., Ishikawa, T., Shigeoka, S., 2011. Arabidopsis NADPH oxidases, AtrbohD and AtrbohF, are essential for jasmonic acid-induced expression of genes regulated by MYC2 transcription factor. Plant Science, 180(4), 655-660.

Mauck, K.E., Bosque-Pérez, N.A., Eigenbrode, S.D., De Moraes, C.M., Mescher, M.C., 2012. Transmission mechanisms shape pathogen effects on host-vector interactions: evidence from plant viruses. Functional Ecology, 26(5), 1162-1175.

McFall-Ngai, M., Hadfield, M.G., Bosch, T.C., Carey, H.V., Domazet-Lošo, T., Douglas, A.E., Dubilier, N., Eberl, G., Fukami, T., Gilbert, S.F., Hentschel, U., King, N., Kjelleberg, S., Knoll, A.H., Kremer, N., Mazmanian, S.K., Metcalf, J.L., Nealson, K., Pierce, N.E., Rawls, J.F., Reid, A., Ruby, E.G., Rumpho, M., Sanders, J.G., Tautz, D., Wernegreen, J.J., 2013. Animals in a bacterial world, a new imperative for the life sciences. Proceedings of the National Academy of Science of the USA, 110(9), 3229-3236.

Melotto, M., Underwood, W., Koczan, J., Nomura, K., He, S.Y., 2006. Plant stomata function in innate immunity against bacterial invasion. Cell, 126(5), 969-980.

Mhamdi, A., Hager, J., Chaouch, S., Queval, G., Han, Y., Taconnat, L., Saindrenan, P., Gouia, H., IssakidisBourguet, E., Renou, J.P., Noctor, G., 2010. Arabidopsis GLUTATHIONE REDUCTASE1 plays a crucial role in leaf responses to intracellular hydrogen peroxide and in ensuring appropriate gene expression through both salicylic acid and jasmonic acid signaling pathways. Plant Physiology, 153(3), 1144-1160.

Mignon, J., Haubruge, E., Gaspar, Ch., 1998. Effect of ice-nucleating bacteria (Pseudomonas syringae Van Hall) on insect susceptibility to sub-zero temperatures. Journal of Stored Products Research, 34(1), 8186.

Miller, G., Schlauch, K., Tam, R., Cortes, D., Torres, M.A., Shulaev, V., Dangl, J.L., Mittler, R., 2009. The plant NADPH oxidase RBOHD mediates rapid systemic signaling in response to diverse stimuli. Science Signaling, 2(84), ra45.

Misas-Villamil, J.C., Kolodziejek, I., van der Hoorn, R.A., 2011. Pseudomonas syringae colonizes distant tissues in Nicotiana benthamiana through xylem vessels. Plant Journal, 67(5), 774-782.

Mittapalli, O., Neal, J.J., Shukle, R.H., 2007a. Antioxidant defense response in a galling insect. Proceedings of the National Academy of Science of the USA, 104, 1889-1894.

Mittapalli, O., Neal, J.J., Shukle, R.H., 2007b. Tissue and life stage specificity of glutathione S-transferase expression in the Hessian fly, Mayetiola destructor: implications for resistance to host allelochemicals. Journal of Insect Science, 7, 1-13.

Mittapalli, O., Sardesai, N., Shukle, R.H., 2007c. cDNA cloning and transcriptional expression of a peritrophin-like gene in the Hessian fly, Mayetiola destructor [Say]. Archives of Insect Biochemistry and Physiology, 64, 19-29.

Mitter, C., Farrell, B., Wiegmann, B., 1988. The phylogenetic study of adaptive zones: has phytophagy promoted insect diversification? American Naturalist, 132(1), 107-128.

Miya, A., Albert, P., Shinya, T., Desaki, Y., Ichimura, K., Shirasu, K., Narusaka, Y., Kawakami, N., Kaku, H., Shibuya, N., 2007. CERK1, a LysM receptor kinase, is essential for chitin elicitor signaling in Arabidopsis. Proceedings of the National Academy of Science of the USA, 104(49), 19613-19618. 
Morris, C.E., Sands, D.C., Vinatzer, B.A., Glaux, C., Guilbaud, C., Buffière, A., Yan, S., Dominguez, H., Thompson, B.M., 2008. The life history of the plant pathogen Pseudomonas syringae is linked to the water cycle. ISME Journal, 2(3), 321-334

Mühlenbock, P., Szechyńska-Hebda, M., Płaszczyca, M., Baudo, M., Mateo, A., Mullineaux, P.M., Parker, J.E., Karpińska, B., Karpiński, S., 2008. Chloroplast signaling and LESION SIMULATING DISEASE1 regulate crosstalk between light acclimation and immunity in Arabidopsis. Plant Cell, 20(9), 2339-2356.

Müller, R., de Vos, M., Sun, J.Y., Sønderby, I.E., Halkier, B.A., Wittstock, U., Jander, G., 2010. Differential effects of indole and aliphatic glucosinolates on lepidopteran herbivores. Journal of Chemical Ecology, 36(8), 905-913.

Nishimura, M.T., Stein, M., Hou, B.H., Vogel, J.P., Edwards, H., Somerville, S.C., 2003. Loss of a callose synthase results in salicylic acid-dependent disease resistance. Science, 301(5635), 969-972.

O'Brien, J.A., Daudi, A., Butt, V.S., Bolwell, G.P., 2012a. Reactive oxygen species and their role in plant defence and cell wall metabolism. Planta, 236(3), 765-779

O'Brien, J.A., Daudi, A., Finch, P., Butt, V.S., Whitelegge, J.P., Souda, P., Ausubel, F.M. and Bolwell, G.P., 2012b. A peroxidase-dependent apoplastic oxidative burst in cultured Arabidopsis cells functions in MAMP-elicited defence. Plant Physiology, 158(4), 2013-2017.

O'Connor, T., Humphrey, P.T., Lapoint, R.T., Whiteman, N.K., O'Grady, P.M., 2014. Microbial interactions and the ecology and evolution of Hawaiian Drosophilidae. Frontiers in Microbiology, doi: 10.3389/fmicb.2014.00616.

Palukaitis, P., Groen, S.C., Carr, J.P., 2013. The Rumsfeld paradox: some of the things we know that we don't know about plant virus infection. Current Opinion in Plant Biology, 16(4), 513-519.

Parisy, V., Poinssot, B., Owsianowski, L., Buchala, A., Glazebrook, J., Mauch, F., 2007. Identification of PAD2 as a gamma-glutamylcysteine synthetase highlights the importance of glutathione in disease resistance of Arabidopsis. Plant Journal, 49(1), 159-172.

Park, S.W., Li, W., Viehhauser, A., He, B., Kim, S., Nilsson, A.K., Andersson, M.X., Kittle, J.D., Ambavaram, M.M., Luan, S., Esker, A.R., Tholl, D., Cimini, D., Ellerström, M., Coaker, G., Mitchell, T.K., Pereira, A., Dietz, K.J., Lawrence, C.B., 2013. Cyclophilin 20-3 relays a 12-oxo-phytodienoic acid signal during stress responsive regulation of cellular redox homeostasis. Proceedings of the National Academy of Sciences of the USA, 110(23), 9559-9564.

Pogány, M., von Rad, U., Grün, S., Dongó, A., Pintye, A., Simoneau, P., Bahnweg, G., Kiss, L., Barna, B., Durner, J., 2009. Dual roles of reactive oxygen species and NADPH oxidase RBOHD in an ArabidopsisAlternaria pathosystem. Plant Physiology, 151(3), 1459-1475.

R Core Development Team, 2012. R: a language and environment for statistical computing.

Sarkar, S.F., Gordon, J.S., Martin, G.B., Guttman, D.S., 2006. Comparative genomics of host-specific virulence in Pseudomonas syringae. Genetics, 174(2), 1041-1056.

Sawicki, R., Singh, S.P., Mondal, A.K., Benes, H., Zimniak, P., 2003. Cloning, expression and biochemical characterization of one Epsilon-class (GST-3) and ten Delta-class (GST-1) glutathione S-transferases from 
Drosophila melanogaster, and identification of additional nine members of the Epsilon class. Biochemical Journal, 370(Pt 2), 661-669.

Schlaeppi, K., Bodenhausen, N., Buchala, A., Mauch, F., Reymond, P., 2008. The glutathione-deficient mutant pad2-1 accumulates lower amounts of glucosinolates and is more susceptible to the insect herbivore Spodoptera littoralis. Plant Journal, 55(5), 774-786.

Stintzi, A., Weber, H., Reymond, P., Browse, J., Farmer, E.E., 2001. Plant defense in the absence of jasmonic acid: the role of cyclopentenones. Proceedings of the National Academy of Sciences of the USA, 98(22), 12837-12842.

Sugio, A., Kingdom, H.N., MacLean, A.M., Grieve, V.M., Hogenhout, S.A., 2011. Phytoplasma protein effector SAP11 enhances insect vector reproduction by manipulating plant development and defense hormone biosynthesis. Proceedings of the National Academy of Sciences of the USA, 108(48), E1254E1263.

Summers, C.B., Felton, G.W., 1998. Peritrophic envelope as a functional antioxidant. Archives of Insect Biochemistry and Physiology, 32, 131-142.

Sykiotis, G.P., Bohmann, D., 2008. Keap1/Nrf2 signaling regulates oxidative stress tolerance and lifespan in Drosophila. Developmental Cell, 14(1), 76-85.

Taki, N., Sasaki-Sekimoto, Y., Obayashi, T., Kikuta, A., Kobayashi, K., Ainai, T., Yagi, K., Sakurai, N., Suzuki, H., Masuda, T., Takamiya, K., Shibata, D., Kobayashi, Y., Ohta, H., 2005. 12-oxo-phytodienoic acid triggers expression of a distinct set of genes and plays a role in wound-induced gene expression in Arabidopsis. Plant Physiology, 139(3), 1268-1283.

Tang, C.-S., Bhothipaksa, K., Frank, H.A., 1972. Bacterial degradation of benzyl isothiocyanate. Applied Microbiology, 23(6), 1145-1148.

Thaler, J.S., Humphrey, P.T., Whiteman, N.K., 2012. Evolution of jasmonate and salicylate signal crosstalk. Trends in Plant Science, 17(5), 260-270.

Torres, M.A., Dangl, J.L., Jones, J.D.G., 2002. Arabidopsis gp91phox homologues AtrbohD and AtrbohF are required for accumulation of reactive oxygen intermediates in the plant defense response. Proceedings of the National Academy of Sciences of the USA, 99(1), 517-522.

Torres, M.A., Jones, J.D.G., Dangl, J.L., 2005. Pathogen-induced, NADPH oxidase-derived reactive oxygen intermediates suppress spread of cell death in Arabidopsis thaliana. Nature Genetics, 37(10), 11301134.

Torres, M.A., Jones, J.D.G., Dangl, J.L., 2006. Reactive oxygen species signaling in response to pathogens. Plant Physiology, 141(2), 373-378.

Traw, M.B., Bergelson, J., 2003. Interactive effects of jasmonic acid, salicylic acid, and gibberellin on induction of trichomes in Arabidopsis. Plant Physiology, 133(3), 1367-1375.

Tsuda, K., Sato, M., Stoddard, T., Glazebrook, J., Katagiri, F., 2009. Network properties of robust immunity in plants. PLoS Genetics, 5(12), e1000772. 
Vatamaniuk, O.K., Mari, S., Lu, Y.P., Rea, P.A., 1999. AtPCS1, a phytochelatin synthase from Arabidopsis: isolation and in vitro reconstitution. Proceedings of the National Academy of Sciences of the USA, 96(12), 7110-7115.

Vicente, C.S., Ikuyo, Y., Mota, M., Hasegawa, K., 2013. Pinewood nematode-associated bacteria contribute to oxidative stress resistance of Bursaphelenchus xylophilus. BMC Microbiology, 13, 299.

Vogel, J., Somerville, S., 2000. Isolation and characterization of powdery mildew-resistant Arabidopsis mutants. Proceedings of the National Academy of Sciences of the USA, 97(4), 1897-1902.

Wang, L., Mitra, R.M., Hasselmann, K.D., Sato, M., Lenarz-Wyatt, L., Cohen, J.D., Katagiri, F., Glazebrook, J., 2008. The genetic network controlling the Arabidopsis transcriptional response to Pseudomonas syringae pv. maculicola: roles of major regulators and the phytotoxin coronatine. Molecular Plant Microbe Interactions, 21(11), 1408-1420.

Wasternack, C., Hause, B., 2013. Jasmonates: biosynthesis, perception, signal transduction and action in plant stress response, growth and development. An update to the 2007 review in Annals of Botany. Annals of Botany, 111(6), 1021-1058.

Whiteman, N.K., Gloss, A.D., Sackton, T.B., Groen, S.C., Humphrey, P.T., Lapoint, R.T., Sonderby ,I.E., Halkier, B.A., Kocks, C., Ausubel, F.M., Pierce, N.E., 2012. Genes involved in the evolution of herbivory by a leaf-mining, Drosophilid fly. Genome Biology and Evolution, 4, 788-804.

Whiteman, N.K., Groen, S.C., Chevasco, D., Bear, A., Beckwith, N., Gregory, T.R., Denoux, C., Mammarella, N.D., Ausubel, F.M., Pierce, N.E. 2011. Mining the plant-herbivore interface with a leafmining Drosophila of Arabidopsis. Molecular Ecology, 20, 995-1014.

Wildermuth, M.C., Dewdney, J., Wu, G., Ausubel, F.M., 2001. Isochorismate synthase is required to synthesize salicylic acid for plant defence. Nature, 414(6863), 562-565.

Wu, J., Wang, L., Wünsche, H., Baldwin, I.T., 2013. Narboh D, a respiratory burst oxidase homolog in Nicotiana attenuata, is required for late defense responses after herbivore attack. Journal of Integrative Plant Biology, 55(2), 187-198.

Xiang, C., Oliver, D.J., 1998. Glutathione metabolic genes coordinately respond to heavy metals and jasmonic acid in Arabidopsis. Plant Cell, 10(9), 1539-1550.

Xiang, T., Zong, N., Zou, Y., Wu, Y., Zhang, J., Xing, W., Li, Y., Tang, X., Zhu, L., Chai, J., Zhou, J.M., 2008. Pseudomonas syringae effector AvrPto blocks innate immunity by targeting receptor kinases. Current Biology, 18(1), 74-80.

Yi, S.Y., Shirasu, K., Moon, J.S., Lee, S.-G., Kwon, S.-Y., 2014. The activated SA and JA signaling pathways have an influence on flg22-triggered oxidative burst and callose deposition. PLoS ONE, 9(2), e88951.

Zhang, H., Dugé de Bernonville, T., Body, M., Glevarec, G., Reichelt, M., Unsicker, S., Bruneau, M., Renou, J.-P., Huguet, E., Dubreuil, G., Giron, D., this issue. Leaf-ming by Phyllonorycter blancardella reprograms the host-leaf transcriptome to modulate phytohormones associated with nutrient mobilization and plant defense. Journal of Insect Physiology. 
Zhang, J., Shao, F., Li, Y., Cui, H., Chen, L., Li, H., Zou, Y., Long, C., Lan, L., Chai, J., Chen, S., Tang, X., Zhou, J.M., 2007. A Pseudomonas syringae effector inactivates MAPKs to suppress PAMP-induced immunity in plants. Cell Host \& Microbe, 1(3), 175-185.

Zhao, C., Shukle, R., Navarro Escalente, L., Chen, M., Richards, S., Stuart, J.J., this issue. Avirulence gene mapping in the Hessian fly (Mayetiola destructor) reveals a protein phosphatase $2 \mathrm{C}$ effector gene family. Journal of Insect Physiology.

Zhou, N., Tootle, T.L., Tsui, F., Klessig, D.F., Glazebrook, J., 1998. PAD4 functions upstream from salicylic acid to control defense responses in Arabidopsis. Plant Cell, 10(6), 1021-1030.

Ziebell, H., Murphy, A.M., Groen, S.C., Tungadi, T., Westwood, J.H., Lewsey, M.G., Moulin, M., Kleczkowski, A., Smith, A.G., Stevens, M., Powell, G., Carr, J.P., 2011. Cucumber mosaic virus and its 2b RNA silencing suppressor modify plant-aphid interactions in tobacco. Scientific Reports, 1, 187. 

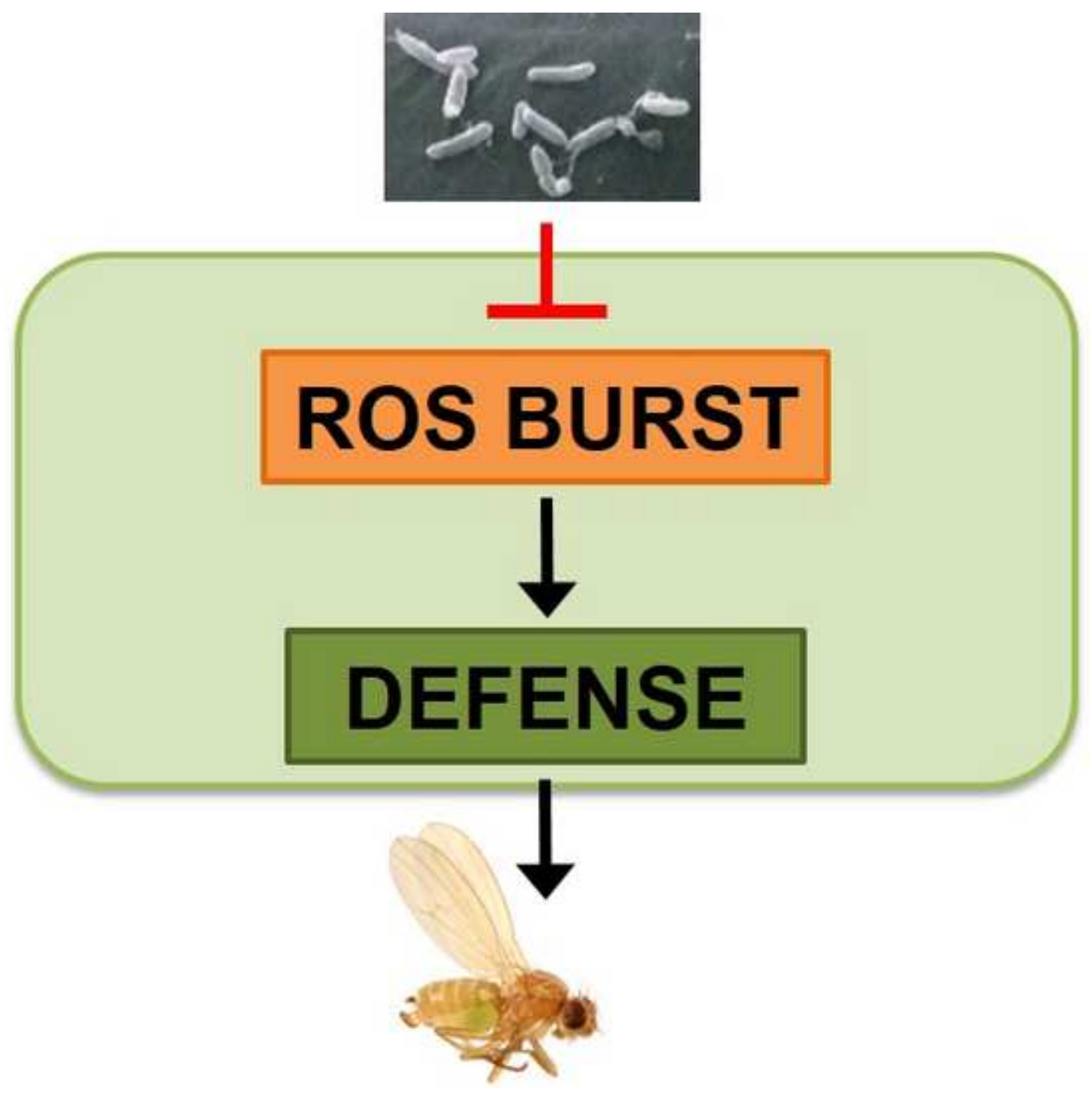